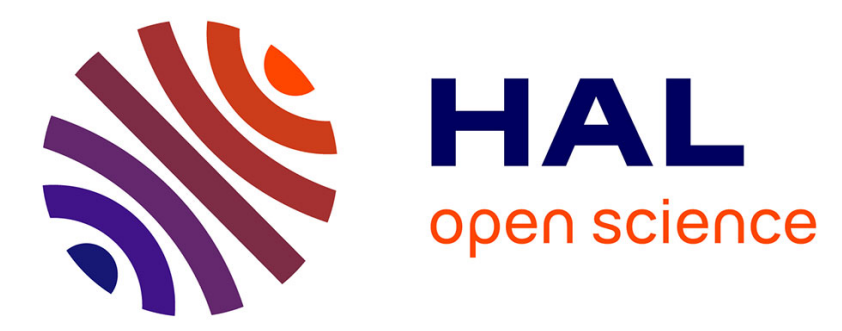

\title{
Study of in vivo catheter biofilm infections using pediatric central venous catheter implanted in rat
}

Ashwini Chauhan, Jean-Marc Ghigo, Christophe Beloin

\section{To cite this version:}

Ashwini Chauhan, Jean-Marc Ghigo, Christophe Beloin. Study of in vivo catheter biofilm infections using pediatric central venous catheter implanted in rat. Nature Protocols, 2016, 11 (3), pp.525 - 541. 10.1038/nprot.2016.033 . pasteur-01377073

\section{HAL Id: pasteur-01377073}

https://hal-pasteur.archives-ouvertes.fr/pasteur-01377073

Submitted on 6 Oct 2016

HAL is a multi-disciplinary open access archive for the deposit and dissemination of scientific research documents, whether they are published or not. The documents may come from teaching and research institutions in France or abroad, or from public or private research centers.
L'archive ouverte pluridisciplinaire HAL, est destinée au dépôt et à la diffusion de documents scientifiques de niveau recherche, publiés ou non, émanant des établissements d'enseignement et de recherche français ou étrangers, des laboratoires publics ou privés.

\section{다)(1) $(5$}

Distributed under a Creative Commons Attribution - NonCommerciall 4.0 International 


\section{Study of in vivo catheter biofilm infections using pediatric central}

2 venous catheter implanted in rat

3 Ashwini Chauhan, Jean-Marc Ghigo and Christophe Beloin*

4 Institut Pasteur, Unité de Génétique des Biofilms, Département de Microbiologie

$5 \quad$ F--75015 Paris, France.

6 * christophe.beloin@pasteur.fr

8 ABSTRACT:

9 Venous access catheters used in clinics are prone to biofilm contamination, contributing 10 to chronic and nosocomial infections. So far, biofilm physiology was mostly studied in 11 vitro, due to a relative lack of clinically relevant in vivo models. Here, we provide a 12 relevant protocol of totally implantable venous access port (TIVAP) implanted in rats. 13 This model recapitulates all phenomena observed in clinic and allows studying bacterial 14 biofilm development and physiology. After TIVAP implantation and inoculation with 15 luminescent pathogens, in vivo biofilm formation can be monitored in situ and biofilm 16 biomass can be recovered from contaminated TIVAP and organs. We used this protocol 17 to study host responses to biofilm-infection, to evaluate preventive and curative anti18 biofilm strategies, and to study fundamental biofilm properties. For this procedure, one 19 should expect $\sim 3 \mathrm{~h} 00$ of hands-on time including the implantation in one rat followed by 20 in situ luminescence monitoring and bacterial load estimation. 


\section{INTRODUCTION:}

Medical devices such as peripheral or central venous catheters, urinary catheters or prostheses are nowadays essential to modern medicine and greatly improve patients' healthcare. These devices are however prone to contamination by microbial pathogens leading to biofilm formation and biofilm-related infections that are extremely difficult to eradicate due to the high tolerance of biofilms towards antibiotics and host immune defenses ${ }^{1}$. Currently, there is no efficient method for early biofilm detection, prevention or eradication besides traumatic and costly removal or replacement of contaminated devices $^{2-5}$. Therefore, there is a dire need for specific and timely detection of biofilm formation on medical devices. However, the development of new strategies aiming at prevention or eradication of chronic and nosocomial biofilm infections require relevant biofilm models and approaches to provide a better understanding of the dynamics of biofilm formation and physiology.

\section{Device associated biofilm animal models}

A large number of in vitro models have been used to study biofilm formation and physiology or for large-scale anti-biofilm drug screening ${ }^{6-11}$. Although useful, these in vitro models do not reproduce the complex interactions occurring in the deviceassociated infection milieu comprising microorganisms, the host and the contaminated abiotic surface. These therefore do not provide access to important parameters when characterizing pathogenic biofilms, host factors and other biotic signals. By contrast, only few in vivo models have been developed to study bacterial biofilm formation associated with central venous catheter (CVC). One of the first corresponding models used vascular catheter inserted in the jugular vein of rat and was developed to study Staphyloccus aureus and Staphyloccus epidermidis biofilm-related infections and to evaluate the efficacy of several antimicrobial agents, including antibiotics and anti-microbial peptides 7,10-15. Other CVC models using different hosts include a mice model catheterized in the jugular vein used to study the role of alternative SigB in $S$. aureus virulence ${ }^{16}$, or a precatheterized (jugular vein) mice model to study the eradication efficacy of lysostaphin against $S$. aureus biofilm ${ }^{17}$. Using rabbit, port access venous catheters inserted in the jugular vein were used to test several antibiotic against $S$. aureus ${ }^{18}$. Finally, several animal models were also developed to study Candida albicans biofilm-related infections, an important causative agent of CVC-related infections ${ }^{19-22}$. All these studies were invasive in nature and required animal killing in order to assess and quantify colonization 
1 the vascular circulation, subcutaneously implanted mice CVC biofilm models were

2 described using luminescent variants of S. aureus, S. epidermidis and Pseudomonas aeruginosa for real-time monitoring of biofilm formation ${ }^{23,24}$ and dissemination ${ }^{25}$. However, these models do not adequately reflect real clinical situation and do not take into account key host factors such as venous blood circulation or humoral factors.

\section{Overview of the proposed in vivo catheter biofilm model protocol}

To better understand device associated biofilm infections, our laboratory has optimized a long-term central venous catheter model using commercial pediatric Totally Implantable Venous Access Ports (TIVAP) inserted in rat jugular veins ${ }^{26-28}$. Unlike other venous catheters used in other in vivo studies, TIVAP are closed devices accessible through a port implanted subcutaneously and connected to the central venous system via a catheter usually inserted into the jugular or subclavian vein. In our model, the TIVAP is subcutaneously implanted with the port secured in a pocket, at the dorsal midline towards the end of thoracic vertebrae. Luminescent variants of clinically relevant bacteria forming biofilm on biomaterial are introduced into the port by puncturing the silicone septum using Huber needles. Then, bacterial colonization and biofilm formation is monitored, without further invasive intervention, as a function of luminescence using charge-coupled device (CCD) camera. We optimized the inoculum size to be $1 \times 10^{4}$ CFU/50 $\mu \mathrm{L}$ per port for $E$. coli and $1 \times 10^{6} \mathrm{CFU} / 50 \mu \mathrm{L} S$. aureus and $P$. aeruginosa. Increased bioluminescence signals were correlated to higher bacterial titers within TIVAP. At these dosages we were able to measure the signals associated with chronic biofilms up to 120 days. This animal model was successfully used to study the colonization of venous catheters by clinically relevant pathogens ( $S$. aureus, $S$. epidermidis, $P$. aeruginosa and E. coli) ${ }^{26-30}$.

Biofilm biomass formed in the TIVAP can be determined quantitatively by harvesting the bacteria as discussed in details below and plating on suitable agar plates. Counts of viable bacteria ranging from 7.6 to $8.3-\log \mathrm{CFU} / \mathrm{mL}$ (port) and 7.5 to $9.2-\operatorname{logs} \mathrm{CFU} / \mathrm{mL}$ (catheter) were obtained in the TIVAP. The bacterial load in the organs (lungs, heart, spleen, kidneys, liver or blood) can also be determined by plating tissue homogenates. To complement microbiological methods assessing biofilm pathogenesis in the rat TIVAP model, electron microscopy was used in order to visualize biofilm structures growing on the lumen of the catheter and on the silicone septum of the TIVAP. Furthermore, we also optimized cyclophosphamide-based immunosuppression to study the consequences of TIVAP-associated biofilm infection in immunocompromised hosts. 
We showed that our TIVAP rat model recapitulates all phenomena observed in clinical TIVAP-associated biofilm infections and can also be used to study the fundamental mechanisms of in vivo biofilm formation.

TIVAP applications from a clinical point of view:

1. Evaluation of current procedures used to handle TIVAP in clinical settings, including skin disinfection procedures, TIVAP patency maintenance ${ }^{26}$, etc.

2. Study of the different routes of TIVAP colonization in addition to classical endoluminal colonization including:

i/ extra-luminal colonization of the catheter;

ii/ extra-luminal colonization of the port leading to subcutaneous port pocket infection, a clinical situation where repeated intradermal needle punctures during access to TIVAP may lead to subcutaneous bacterial port pocket infection ${ }^{31}$ (20\% of TIVAP-implanted rats inoculated with $P$. aeruginosa or $S$. aureus developed subcutaneous infection around port ${ }^{27}$ );

iii/ catheter tip colonization via hematogenous route of infection, a situation observed when TIVAP implanted patients suffer from bloodstream infection: TIVAP implanted rats injected with $S$. aureus in the tail vein showed colonization of TIVAP catheter tip ${ }^{27}$. Furthermore, we observed, in our TIVAP rat model, chronic colonization of implanted devices with occasional catheter-related bloodstream infections as detected in CVC bearing patients ${ }^{27}$. Thus, our rat TIVAP model successfully reproduced clinical situations such as biofilm-related bloodstream infections, organs colonization and port-pocket infections.

3. Investigation of controlled chronic infection and recurrence of infection after conservative treatment.

4. Development of early biofilm detection methods ("biofilm biomarkers"). Such biomarkers are currently lacking and their identification could strongly facilitate medical decisions.

5. Evaluation of prophylactic strategies including:

i/ novel catheter lock solutions. The catheter lock therapy corresponds to the use of highly concentrated antimicrobial (often antibiotic) solutions that dwell inside the catheter for at least 12 to 24 hours ${ }^{32}$;

ii/ catheter treatment with anti-adhesive procedure ${ }^{26}$. We modified the surface of commercial TIVAPs composed of silicone and titanium, using methyl cellulose $(\mathrm{MeCe})$ as well as polyethylene glycol (PEG), two macromolecules with 
described anti-adhesive activities ${ }^{33,34}$. Using our rat model of biofilm infections inoculated with bioluminescent bacteria, we showed that an anti-adhesive approach could constitute an efficient prophylactic strategy to control infections in medical devices;

$\mathrm{iii} /$ anti-biofilm strategies against biofilm-related infection such as vaccination.

6. Evaluation of curative strategies against difficult-to-treat pathogens $(P$. aeruginosa, methicillin resistant $S$. aureus, possibly $C$. albicans), for which the current clinical recommendation in case of device-related infection is costly and traumatic removal of the device. These curative strategies include:

i/ curative catheter lock solutions active on already developed infectious biofilms $27,28,30$. We used EDTA as adjuvant in combination with gentamicin as a lock solution to eradicate all the bacterial biofilms tested using our rat TIVAP model ${ }^{28}$ and L-arginine, a basic amino-acid, combined with gentamicin to eradicate $S$. aureus and $E$. coli in vivo biofilms ${ }^{30}$;

ii/ novel anti-biofilm molecules;

iii/ alternative strategies (ultrasonic waves, photodynamic or phage therapies).

7. Evaluation of anti-thrombotic treatments since thrombosis is observed using this model ${ }^{26}$. Previous studies showed that biofilm colonized implanted catheters are at higher risk of causing thrombosis ${ }^{35}$. We used our model to demonstrate the better patency in the TIVAP coated with anti-adhesive coatings compared to control untreated TIVAPs ${ }^{26}$.

TIVAP applications from a fundamental point of view:

1. Study of biofilm physiology in vivo and in a clinically relevant model amenable to transcriptomic, proteomic or metabolomic analyses. Biofilm-specific properties such as biofilm-associated production of molecules ${ }^{29}$ or biofilm-specific increased recalcitrance to antimicrobial agents and to the immune system can be studied using this model.

2. Evaluation of the in vivo role of biofilm-promoting factors identified in vitro.

3. In vivo study of clinically relevant biofilm-forming microorganisms other than bacteria, in particular $C$. albicans, one of the main causes of catheter-related infection.

4. Investigation of the impact of the implanted host immune system on the development of in vivo biofilms ${ }^{27}$ and, reciprocally, study of the impact of biofilm development on the immune system. 


\section{Experimental Design}

4 Overview of the procedure stages

The procedure described is designed to study bacterial biofilms using a central venous catheter called TIVAP inserted in rat jugular vein. The study can be broadly divided into 6 stages (see Flow chart of the different steps is presented in Figure 1): One animal study takes between 2-3 weeks but may be longer depending on the question to be addressed, for example immunosuppression of animals will add another 4 days to a study. A trained engineer, PhD student, post-doctoral fellow or researcher can perform all stages of the procedure.

1) Pre-surgical procedures: After reception of the rats, they are transferred 2 per cage and housed in animal facility. They are given pain-killers in specialized gels prior to surgery.

2) Surgery (TIVAP implantation): TIVAP is implanted subcutaneously with catheter inserted into the jugular vein.

3) Postsurgical care: Animals are allowed to recover from surgery before injecting bacteria in the port. During this time of recovery, the patency of TIVAP is maintained by "flush and draw" technique to mimic clinical TIVAP use, and the temperature and weight of the animals are regularly monitored.

4) Bacterial challenge: Four days post-surgery, TIVAP is contaminated via controlled bacterial inoculation through the port by bacteria that are allowed to adhere to the device surface (internal) for certain duration of time before the inoculum is removed.

5) Post challenge care and monitoring: The biofilm is allowed to form on the device up to day1, day4, day10 or even up to 120 days, depending on the question addressed. Blood sampling is done at day 0 (before inoculation to ensure TIVAP sterility); day 4 and day 8 to analyze the TIVAP mediated infection. Animals are monitored for the clinical symptoms.

30 6) Euthanasia and sampling: On the day of experiment termination, animals are euthanized and the TIVAP and organs are aseptically removed for analysis.

\section{Laboratory facilities}

34 All the described animal work was done in the Institute Pasteur animal facilities, which

35 are accredited by the French Ministry of Agriculture to perform experiments on live 36 rodents (accreditations A75-15 27, issued 12 November 2004, and A75-15 04, issued 22 
1 May 2008). Work on animals was performed in compliance with French and European

2 regulations on care and protection of laboratory animals (European Commission

3 directive 2010/63; French law 2013-118, 06th February, 2013). The protocols used in

4 this study were approved by the ethics committee of "Paris Centre et Sud $N^{\circ} 59^{\prime}$

5 (reference 2012-0045). All methods are performed in a 'Biosafety Level-2' facility,

6 containing a Class II biosafety cabinet. Aseptically collected samples (TIVAP, organs or

7 blood) from animals can be processed in the main laboratory inside a Class II biosafety

8 cabinet to maintain sterility. The animal room is cleaned with disinfectant every day until

9 the end of a study.

\section{Controls}

12 Proper controls must be used in the study. For each study, uninfected animal control 13 with implanted TIVAP should be used as biofilm negative controls. For testing 14 antimicrobials, $1 \mathrm{X}$ PBS or other appropriate reagent control must be used to compare 15 the efficacy of the tested compounds.

\section{Anesthesia optimization}

Anesthetics are critical to sedate rat and reduce discomfort during surgery as well as during follow-up procedures. For example, rats treated with cyclophosphamide have different susceptibilities to anesthesia (isoflurane) induced hypoxia; therefore, empirical determination of chemical anesthesia and/or isoflurane dosages is required. We have optimized ketamine, xylazine and acepromazine mix $(7: 2: 1, \mathrm{v} / \mathrm{v})$ injected intraperitoneally to $500 \mu \mathrm{L}$ cocktail/300grams of rat weight. Acepromazine keeps the rats calm and allows additional injections during the surgery, if needed. Isoflurane concentration for healthy rats was optimized to $3 \%$ for the induction of anesthesia and maintenance of the anesthetic state at an oxygen flow-rate of $0.8 \mathrm{~L} / \mathrm{min}$ and air flow-rate of $0.4 \mathrm{~L} / \mathrm{min}$ to get a total debit of 1.2. Isoflurane concentration for immunosuppressed rats was optimized to $1.5 \%-2.0 \%$ for the induction of anesthesia and $1.5 \%$ for maintenance of the anesthetic state at an oxygen flow-rate of $0.6 \mathrm{~L} / \mathrm{min}$ and air flow-rate of $0.4 \mathrm{~L} / \mathrm{min}$ to get a total debit of $1.0 \mathrm{~L} / \mathrm{min}$.

Critical step: Isoflurane is an inhalation anesthetics found under several trade names such as aerrane, floran, florane, isothane etc. It provides a quick, easy and long lasting effect when provided continuously to the research animals. Prolonged exposures in animals need to be regulated and monitored closely to prevent death. Injectable anesthetics, such as ketamine-xylazine-acepromazine mixture can be used for long- 
1 term (up to $45 \mathrm{~min}$ ) sedation of rats. Ketamine and acepromazine are controlled

2 substances, which require secured storage and proper records of usage.

3 CAUTION: Isoflurane is a halogenated ether. It is a colorless liquid anesthetic with a 4 pungent odor. High doses of isoflurane exposure in research animals have been demonstrated to have fetal toxic effects. Pregnant women are recommended not to use it unless other means of anesthesia are not available and, in such case, special masks need to be worn. Only an approved anesthetic respirator system approved by the ethical committee should be used. Also make sure to work in well-ventilated area when using isoflurane or any other inhalation anesthetics.

\section{Choice of Animals}

12 We chose Crl:CD/SD variant of wistar rats for our study as they are recommended for studying infectious diseases. The rats are 250-275 grams at reception day and gain $\sim 50$ grams by the day of surgery.

Note: Wistar rats may also be used for the study.

\section{Choice of Microbes}

18 Luminescent variants of four clinically relevant pathogens, i.e. E. coli, P. aeruginosa, S. aureus and S. epidermidis were purchased (S. aureus Xen36, Xen30, Xen31 and S. epidermidis Xen43 from Caliper) or gifted ( $P$. aeruginosa Lm1, a bioluminescent derivative of the PAK clinical strain ${ }^{36}$ and E. coli EAEC $55989{ }^{37}$ transformed with stable plasmid pAT881) ${ }^{38}$. E. coli and $P$. aeruginosa strains were grown in Lysogeny broth (LB); S. aureus Xen36 and S. epidermidis Xen43 were cultured in Tryptic Soy broth (TSB) supplemented with $0.2 \%$ glucose at $37^{\circ} \mathrm{C}$. Other relevant bacteria may also be studied within this model. While bioluminescence is an efficient tool to follow in situ colonization of the device and potential dissemination, it is also possible to estimate endpoint bacterial load using non-bioluminescent microbial variant.

\section{Optimization of inoculum size and volume}

30 The inoculum dose was optimized to $10^{4}$ cells for $E$. coli, $10^{6}$ cells for $P$. aeruginosa and

31 S. aureus. For $S$. epidermidis the maximum dose that could be used was $10^{8}$ cells but did not lead to bioluminescent-detectable colonization. Currently no other bioluminescent strain of $S$. epidermidis is available ${ }^{24}$. The volume of the inoculum was optimized to $50 \mu \mathrm{L}$ per TIVAP. The dead volume of the port is $250 \mu \mathrm{L}$. This insures that no bacteria are flushed into the blood stream at the time of inoculation. 


\section{Antibacterial agents}

2 The described methods were successfully used in our model to test the antibiofilm 3 activity of cefazolin, gentamicin, EDTA, ethanol (70\%) and L-arginine, injected alone or 4 in certain combination in catheter lock solutions ${ }^{27,28,30}$. Moreover, our model was 5 successfully used to evaluate the anti-adhesion characteristics of biomimetic glycocalyx6 like polymer such as methylcellulose ${ }^{26}$. Empirically, the effect of any relevant 7 antimicrobial agents or anti-adhesive molecules can be evaluated using our model. In 8 vitro concentration of the antimicrobial agents and procedures to graft anti-adhesive 9 molecules on silicone and/or titanium need to be verified before in vivo evaluation in rat 10 TIVAP model. 
2 MATERIALS

Reagents:

4

\begin{tabular}{|c|c|c|}
\hline Product & Reference & Manufacturer \\
\hline $\begin{array}{l}\text { Sterile 1X Phosphate buffered Saline } \\
\text { (PBS) }\end{array}$ & $10010-023$ & GIBCO \\
\hline Sterile water & $15230-071$ & GIBCO \\
\hline Kanamycin & B5264-1G & Sigma Aldrich \\
\hline Cefazolin & $\begin{array}{l}\text { C5020- } \\
500 M G\end{array}$ & Sigma Aldrich \\
\hline Vancomycin & $94747-5 G$ & Sigma Aldrich \\
\hline Gentamicin & G1914-5G & Sigma Aldrich \\
\hline Lysogeny Broth (LB) & $12795-027$ & Invitrogen \\
\hline L-arginine & A5006-100G & Sigma Aldrich \\
\hline Agar degranulated & 214530 & DIFCO \\
\hline Tryptic Soy broth (TSB) & 211825 & DIFCO \\
\hline Tryptic soy agar (TSA) & 236950 & DIFCO \\
\hline $\begin{array}{l}\text { Ethanol, } 70 \% \text { (made from absolute } \\
\text { alcohol) }\end{array}$ & 34935-1L & Sigma Aldrich \\
\hline Sterile Heparin, $5001 \mathrm{U} / \mathrm{mL}, 5 \mathrm{~mL}$ bottle, & 512507 & Sanofi Aventis \\
\hline Ketamine, Imalgen1000 & IMA004 & Merial SAS Lyon, $\mathrm{Fr}$ \\
\hline Xylazine, (Rompun $\left.{ }^{\mathrm{TM}} 2 \%\right)$ & ROM001 & $\begin{array}{l}\text { Bayer Healthcare, } \\
\text { Germany }\end{array}$ \\
\hline $\begin{array}{l}\text { Acepromazine (Injectable), Calmivet } \\
\text { Solution }\end{array}$ & CAL226 & $\begin{array}{l}\text { Sanofi Aventis, } \\
\text { Lure, FR }\end{array}$ \\
\hline Betadine gel $10 \%$, tube of $100 \mathrm{~g}$ & & Meda Pharma \\
\hline Anesderm $5 \%$, tube of $5 \mathrm{~g}$ & Pharmacy & $\begin{array}{l}\text { Pierre } \quad \text { Fabre, } \\
\text { France }\end{array}$ \\
\hline Betadine solution, bottle of $120 \mathrm{~mL}$ & & Vetoquinol \\
\hline Eye drops, Ocrygel ${ }^{\circledR}$ & 843TVN & \\
\hline Gel, medigelsucralose $56 \mathrm{gm}$ & TPP2270 & Fisher Scientific \\
\hline $\operatorname{Vikron}^{\circledR} 1 \%$ & & Reltyon \\
\hline Sodium pentobarbital, Dolethal & 6847542 & Alcyon France \\
\hline $\begin{array}{l}\text { Isoflurane, IsoVet } 1000 \mathrm{mg} / \mathrm{g} \text { inhalation } \\
\text { vapour (Schering-Plough) }\end{array}$ & $\begin{array}{l}\text { IsoVet } \\
1000 \mathrm{mg} / \mathrm{g}\end{array}$ & Imaxio, France \\
\hline
\end{tabular}




\begin{tabular}{|l|l|l|}
\hline Buprecare $^{\circledR}$ (Ibuprofen) & & Axience, France \\
\hline Cyclophosphamide monohydrate & C0768-5G & Sigma Aldrich \\
\hline Sodium Cacodylate Trihydrate & C0250-100G & Sigma Aldrich \\
\hline Ruthenium red & R2751-1G & Sigma Aldrich \\
\hline Glutaraldehyde 25\% & G5882 & Sigma Aldrich \\
\hline
\end{tabular}

2 Equipments:

\begin{tabular}{|c|c|c|}
\hline Equipments (number needed for the study) & $\begin{array}{l}\text { Catalogue } \\
\text { number }\end{array}$ & Manufacturer \\
\hline $\begin{array}{l}\text { Charged-coupled device CCD Camera (IVIS } \\
100)\end{array}$ & & $\begin{array}{l}\text { Xenogen } \\
\text { Corporation, } \\
\text { Alameda, } \\
\text { CA, USA }\end{array}$ \\
\hline Vet $a b c$ & $A B C$ vet 2.0 & $\begin{array}{l}\text { SCIL, } \\
\text { Germany }\end{array}$ \\
\hline Surgical hood & $\begin{array}{l}\text { FASTER } \\
\text { FLOWFAST } \\
\text { H18 }\end{array}$ & $\begin{array}{l}\text { Faster-air, } \\
\text { France }\end{array}$ \\
\hline Laminar air flow & $\begin{array}{l}\text { Faster } \\
\mathrm{BH} 2006\end{array}$ & $\begin{array}{l}\text { Faster-air, } \\
\text { France }\end{array}$ \\
\hline Hot bead sterilizer & $18000-50$ & $\begin{array}{l}\text { Fine Science } \\
\text { Tools (FST) }\end{array}$ \\
\hline Beads & $18000-51$ & FST \\
\hline Micro spring scissors (1) & $15007-08$ & FST \\
\hline Fine scissors (1) & $14502-14$ & FST \\
\hline Fine forceps (2) & $11245-30$ & FST \\
\hline Blunt forceps (1) & $11000-14$ & FST \\
\hline Hemostats (2) & $130008-12$ & FST \\
\hline Silk Thread, 22.5 meters & $18020-30$ & FST \\
\hline Curved forceps & $91197-00$ & FST \\
\hline $\begin{array}{l}\text { Suture Vicryl 3-0 Polyglactin absorbable, box } \\
\text { of } 36\end{array}$ & V497H & Ethicon \\
\hline $\begin{array}{l}\text { Suture Dafilon } 3 / 0 \text { Polyamide non-absorbable, } \\
\text { box of } 36\end{array}$ & C0935239 & B Braun \\
\hline Scalpel & 0510 & $\begin{array}{l}\text { Swann- } \\
\text { Morton }\end{array}$ \\
\hline
\end{tabular}




\begin{tabular}{|c|c|c|}
\hline TIVAP, Polysite 2000 micro, 5F & 2105 ISP & $\begin{array}{l}\text { Perouse } \\
\text { medical }\end{array}$ \\
\hline Sterile champ & CSO-02NT & $\mathrm{LCH}$ \\
\hline Sterile gloves (size 7-8, medium) & STP641 & $\mathrm{LCH}$ \\
\hline Sterile gauze pad & CNST-470 & $\mathrm{LCH}$ \\
\hline $\begin{array}{l}\text { Huber needle, straight } 7 / 10,22 \mathrm{G}, 30 \mathrm{~mm} \text {, box } \\
\text { of } 50\end{array}$ & 512507 & $\begin{array}{l}\text { Perouse } \\
\text { Medical }\end{array}$ \\
\hline Respiratory Mask, FFP2 & $19-130-4825$ & $\begin{array}{l}\text { Fisher } \\
\text { Scientific }\end{array}$ \\
\hline Sterile gown & 98000622 & $\begin{array}{l}\text { Barrier, } \\
\text { France }\end{array}$ \\
\hline Temperature Controller, with rectal probe & TCAT-2LV & $\begin{array}{l}\text { Physitemp } \\
\text { Instruments } \\
\text { Inc, USA }\end{array}$ \\
\hline Thermocage, animal warming system & MK3 & $\begin{array}{l}\text { Datestand } \\
\text { Ltd., } \\
\text { Manchester, } \\
\text { UK }\end{array}$ \\
\hline IPTT-300, Electronic chip introducer and chip & BV 11059 & $\begin{array}{l}\text { PLEXX, } \\
\text { Europe }\end{array}$ \\
\hline Wireless Reader with round IMI probe & DAS-7006R & $\begin{array}{l}\text { PLEXX, } \\
\text { Europe }\end{array}$ \\
\hline Mozer Max45 clipper & $1245-0066$ & $\begin{array}{l}\text { Moser } \\
\text { animalline }\end{array}$ \\
\hline Isoflurane vaporizer, TAG & TAG1100 & $\begin{array}{l}\text { TEM } \\
\text { (Lormont, } \\
\text { France) }\end{array}$ \\
\hline Conical tubes , $50 \mathrm{~mL}$ & $14-432-22$ & $\begin{array}{l}\text { Fisher } \\
\text { scientific }\end{array}$ \\
\hline Conical tubes , $15 \mathrm{~mL}$ & 14-959-70C & $\begin{array}{l}\text { Fisher } \\
\text { scientific }\end{array}$ \\
\hline Microtubes & $05-402-24 B$ & $\begin{array}{l}\text { Fisher } \\
\text { scientific }\end{array}$ \\
\hline GentleMACS ${ }^{\text {тM }}$ Octo Dissociator & $130-095-937$ & $\begin{array}{l}\text { Miltenyi } \\
\text { Biotec }\end{array}$ \\
\hline GentleMACS $^{\text {TM }} \mathrm{M}$ tubes & $130-096-335$ & Miltenyi \\
\hline
\end{tabular}




\begin{tabular}{|l|l|l|}
\hline & & Biotec \\
\hline Cell strainer 70 $\mu \mathrm{m}$ Nylon & 3523350 & BD Falcon \\
\hline T25 digital ULTRA-TURRAX ${ }^{\circledR}$ homogenizer & 0010001502 & Ika, France \\
\hline NEYtech Ultrasonik, 44-48 Khz & & NEYtech \\
\hline
\end{tabular}
1

2 
PROCEDURE

\section{Step 1: Pre-surgical Procedures}

1A) Day -6 , reception of animals: The CD/SD (IGS:Crl) male rats (CharlesRiver) weigh 275-300grams and are acclimatized to a $12 \mathrm{~h}$ day/night cycle for one week prior to use with commercial feed / tap water ad libitum. (TIMING: Responsibility of Animal Facility)

1B) Day -5 , an electronic chip is inserted in the flank region of rats to monitor the temperature during course of the study. The weight of rats is also monitored on regular basis. (TIMING: 10 min per rat) 1C) Day -2, all the rats are fed with Medigel-sucralose (1cup (56gm) per cage per day) without ibuprofen* for rats to habituate to mixture followed by Medigel+ibuprofen gel on day -1. (TIMING: $10 \mathrm{~min}$ per rat)

Critical step: if given directly with the drug, most of the rats do not eat the pain-killer and can lead to health issues post-surgery. Medigel with ibuprofen can be prepared on day 2 and stored at $4^{\circ} \mathrm{C}$ but brought to room temperature before feeding the rats.

Step 2: Surgical Procedure (TIVAP implantation, day 0) (TIMING: 55min)

2A) Anesthesia (TIMING: 2 minutes per rat, 5-6 minutes for a rat to sleep)

Rats are anesthetized using a $500 \mu \mathrm{L}$ cocktail (per 300grams of rat weight) of ketamine, xylazine and acepromazine mix (7:2:1, v/v) injected intraperitoneally.

2B) Shaving (TIMING: 3-4 minutes per rat)

Once the rat is fully unconscious, closely shave dorsal side of the rat with an electric clipper to remove hair from the neck up to lower end of the thoracic vertebrae and from left to right end of the body (Figure 2). Then, turn the rat on its back and shave the neckline carefully without cutting the skin. Remove any excess hair with the help of a clean paper towel.

Critical step: If the rat is not completely asleep, any procedure including shaving can be stressful leading to death of rat during the procedure. well as surrounding area is gently cleaned in 2 steps: i) wash with betadine soap using a 
sterile gauze pad or any other sterile pad of absorbent material; ii) disinfect with betadine solution. Repeat the cycle 3 times.

2D) Preparation for surgery: (TIMING 15 minutes)

Since it takes $\sim 15$ minutes for a rat to be ready for surgery, meanwhile, arrange and prepare the surgery area. For this,

2D.1) Clean the surgical hood with $70 \%$ ethanol and spread a sterile champ/sheet.

2D.2) On the sheet, place on left corner a pair of Scissors, hemostats (2), spring

2E) Surgery: (TIMING 30-45 minutes per rat, Figure 2 and Figure 3)

2E.1: Once the rat is disinfected, place the rat on the surgical sheet with the dorsal side up and tail away from you. Take some $70 \%$ ethanol and wipe the body of the rat once more. Wear the sterile gloves and avoid touching any surroundings.

2E.2: Make an incision $(\sim 1.5 \mathrm{~cm})$ on dorsal line at the upper end of thoracic vertebrae with a scalpel.

2E.3: Using a scissor, make a subcutaneous pocket inside the incision by opening $\&$ closing the scissor slowly. Make the pocket big enough to easily insert the port of TIVAP.

2E.4: Take the port and insert the pointed end first while pushing the wider part with your thumbs. Once inserted, secure the TIVAP by suturing (using a hemostat to hold the suture and a blunt forceps) inside of the skin with vicryl, 3.0, nonabsorbable suture.

2E.5: Insert Huber needle into the port by puncturing the septum and gently turn the rat on its back. Place a pad of gauze pad wet in 1X PBS.

Critical step: It is important to keep a wet pad of gauze pad on the incision throughout the process to prevent its dehydration. 
2E.6: Make an incision about $1-1.5 \mathrm{~cm}$ in the neck on right hand side with scalpel. Gently try to remove the muscles with a fine forceps to expose the vein. Keep the area wet and clean with $1 \mathrm{X}$ PBS.

2E.7: Locating the vein: Left Jugular vein is situated superficially under the salivary glands and it forms "inverted $Y$ " junction with the right jugular vein, tail of "inverted $Y$ " joining the subclavian vein. Keep the area and veins wet with $1 X$ PBS, all the time.

Critical step: It is important to keep the vein wet because if dried it will lose its flexibility and it will be difficult to make a cut in the vein as well as tough to insert the catheter in vein.

2E.8: Using a curved forceps pass two black silk threads under the external jugular vein. Clamp one on the proximal end (to tie the incised vein) and another on the distal end (to secure the catheter inside the external jugular vein) of the jugular vein with hemostats.

2E.9: Then, try to clean the area surrounding the vein and remove any extra tissues that might be attached to jugular vein. Keep the vein and surrounding area wet with $1 \mathrm{X}$ PBS.

2E.10: After exposing the vein, slightly tilt the rat (gently) and insert the blunt end of tunneling rod (provided in the TIVAP kit) from the dorsal side and push out from the ventral incision in the neck region. On the pointed end put on the catheter and pull it along the tunneling rod on ventral side so as to have catheter tunneled under the skin ready to be inserted in the jugular vein.

2E.11: Cut the catheter to a length of $4.5 \mathrm{~cm}$ (catheter has markings $1 \mathrm{~cm}$ apart) at an angle not more than $30^{\circ}$. This is the length of catheter to be inserted in the external jugular vein to reach the top of right atrium.

Critical step: Cutting the catheter at a higher angle will allow easy insertion of catheter in the jugular vein but it will lose patency quickly due to suction of vein against the bigger tilted cut while pulling the blood with syringe.

2E.12: Make sure that port and catheter are filled with $1 \mathrm{X}$ PBS. For this, fill the TIVAP by slowly pushing the piston of the syringe with Huber needle inserted in to port.

Critical step: It is important to make sure before inserting the catheter in jugular vein that there is no air in the TIVAP as it can kill the rat within few minutes.

2E.13: While gently holding the vein with a fine forceps make a partial cut in the external jugular carefully using a micro spring scissors. 
Critical step: There may be lots of blood flow from the vein. In this case take wet gauze pad and press it against the vein for 2-3 minutes or until the bleeding has stopped. Keep the vein wet using 1 X PBS.

2E.14: Dilate the vein carefully by inserting closed forceps little bit. Once the forceps is inside slowly release to open it, at the same time hold the upper part of the incision with one forceps and insert the catheter using another forceps. Slightly push the catheter inside the vein $(\sim 4.5 \mathrm{~cm})$ followed by flushing $100 \mu \mathrm{L} 1 \mathrm{X}$ PBS in the vein.

Critical step: This step should be done as early as possible as the vein may be dehydrated and become inflexible. This step is most tricky and need lots of practice to insert the catheter. Furthermore there can be blood loss leading to death of rat; hence the insertion must be quick. TROUBLESHOOT

2E.15: Try to gently draw the blood to make sure the reflux and then flush about $500-600 \mu \mathrm{L} 1 \mathrm{X}$ PBS and lock with $250 \mu \mathrm{L}$ heparin $(500 \mathrm{IU} / \mathrm{mL})$. Remove the Huber needle form the port. TROUBLESHOOT

2E.16: Tie the black thread on the distal end on the vein to secure the catheter and proximal thread to block the incised end of the vein.

Critical step: The thread should not be too tight as it can create pressure and prevent the drawing of blood. Also, it should not be lose as the catheter may slip out of the vein.

2E.17: Clean the surgery area and suture dorsal (4-5 stitches) and ventral (3-4 stitches) incisions. Put antiseptic cream such as betadine and local anesthetic lidocaine cream such as Anesderm.

2E.18: Transfer the rat to $39^{\circ} \mathrm{C}$ chamber until wakes up.

2E.19: Finally, transfer the rat into a new cage with new water bottle. Place a cup of Medigel+ibuprofen per cage.

\section{Step 3: Postsurgical care: Day +1 to Day +4}

3A) Feeding Analgesic: New cup of Medigel + ibuprofen is kept in the cage of the rats on day +1 after surgery.

3B) "Flush and draw": (TIMING 4 minutes anesthesia, 5 minutes flush and draw per rat). 3B.1) To maintain the patency of the catheters, the TIVAP is flushed every day until the day of the bacterial challenge. The rat is transferred to the isoflurane box until the induction of anesthesia.

3B.2) Meanwhile, place a sterile sheet in the laminar air flow and place the nose piece connected to the isoflurane system on it. 
3B.3) Place the nose of the anesthetized rat in the nose piece such that the tail is away from you.

3B.4) Clean the skin on and surrounding the port with betadine solution and $70 \%$ ethanol and allow to air dry for 4-5 minutes.

3B.5) Gently insert the Huber needle connected to a $2 \mathrm{~mL}$ syringe filled with $1 \mathrm{X}$ PBS into the port by puncturing silicon septum of the port. 3B.6) Slowly turn the rat on its back keeping the needle inside the port. 3B.7) Carefully inject about $100 \mu \mathrm{L}$ 1X PBS and then check blood reflux by slowly pulling the piston of the syringe. Flush TIVAP with 1.0 to $1.5 \mathrm{~mL} 1 \mathrm{X}$ PBS, followed by locking the TIVAP with $250 \mu \mathrm{L}$ heparin $(250 \mathrm{IU} / \mathrm{mL})$.

3B.8) Clean the skin with betadine solution and put the rat back in the cage.

Critical step: If the rat is not anesthetized completely, the movement of neck may block the blood reflux. If isoflurane system is not available chemical anesthesia can be given to rats. In this case $250 \mu \mathrm{L}$ anesthesia per 500 grams rat is sufficient.

\section{TROUBLESHOOT}

Step 4: Bacterial inoculation and monitoring of biofilm formation using

3C) Clinical signs: Monitor the clinical signs such as local inflammation around the bioluminescence: Day +4 (TIMING 30 minutes per rat) (see Figure 4)

4A) Bacteria preparation: One day before bacterial challenge, start overnight culture of bioluminescent E. coli 55989 or P. aeruginosa in Lysogeny broth and S. aureus (Xen36, Xen30 or Xen31) or S. epidermidis Xen43 in Tryptic soy agar broth at $37^{\circ} \mathrm{C}$ shaking at

4B) Spin $5 \mathrm{~mL}$ culture at $7500 \mathrm{rpm}$ for 10 minutes to pellet bacteria and re-suspend in $5 \mathrm{~mL} 1 \mathrm{X}$ PBS. Wash the culture twice in $5 \mathrm{~mL} 1 \mathrm{X}$ PBS. Finally, resuspend bacteria in $5 \mathrm{~mL}$ 1X PBS and measure optical density at 600nm (OD600nm). 4C) Dilute the bacterial inoculum so as to inject $10^{4} \mathrm{CFU} / 50 \mu \mathrm{L}$ for $E$. coli, $10^{6} \mathrm{CFU} / 50 \mu \mathrm{L}$ for $P$. aeruginosa \& S. aureus Xen36 and $10^{8}$ CFU/50 $\mu$ L for S. epidermidis Xen43. 
1 4D) Record the weight and temperature of rat before anesthesia. Clinical symptoms

2 such as local inflammation at the site of port or in the neck region, any other abnormality such as breathing trouble, weight loss and fever must be recorded. Any sick rat must not be included in the study and should be euthanized.

4E) Anesthetize the rat as described under "flush and draw" method (see step 3B). Meanwhile, spread the sterile sheet in the laminar air flow. Keep betadine solution, $70 \%$ ethanol, sterile gauze pads, $50 \mu \mathrm{L}$ bacterial inoculum in $1 \mathrm{~mL}$ tuberculin graduated syringe, $1 \mathrm{~mL}$ syringe attached with Huber needle and filled with $1 \mathrm{X}$ PBS, $1 \mathrm{~mL}$ syringe filled with $300 \mu \mathrm{L}$ heparin.

4F) Anesthetized rat is transferred to the dark box of IVIS imaging system with a charged coupled device (CCD) camera (Xenogen Corporation, Alameda, CA, USA) for monitoring bioluminescence before bacterial challenge.

4G) After imaging, transfer rat to the hood for infection. Place rat with its nose inside the nose piece and tail away from you. Clean the skin on and surrounding the port with betadine solution and $70 \%$ ethanol and allow to air dry for $4-5$ minutes. Gently insert the Huber needle connected to a $2 \mathrm{~mL}$ syringe filled with $1 \mathrm{X}$ PBS into the port by puncturing silicon septum of the port. Slowly turn rat on its back keeping the needle inside the port. Slightly inject about $50 \mu \mathrm{L}-100 \mu \mathrm{L} 1 \mathrm{X}$ PBS and then check blood reflux by slowly pulling the piston of the syringe. Remove the syringe keeping the Huber needle inside the port and replace with a syringe to withdraw $150 \mu \mathrm{L}$ blood for analysis. Replace this syringe also with another one containing bacterial inoculum. Slowly push inoculum into the port. Normally this should take 2 minutes. Critical step: If the TIVAP is not patent, do not use it for the study. The blood sample is important to check contamination of TIVAP during the post-surgical maintenance. Care should be taken while taking out the needle out of the port to prevent injecting yourself with bacteria. This procedure is always done under the hood if using Class II pathogens. Injection of inoculum must be very slow to avoid flushing bacteria into the stream.

4H) After bacterial challenge, rat is again transferred to the dark box of IVIS imaging system with a charged-coupled device (CCD) camera (Xenogen Corporation, Alameda, CA, USA) for monitoring bioluminescence. The rats (with $1 \mathrm{X} P B S$ ) are used as uninfected controls.

4I) Rat is then carefully placed back into the cage. Label the cage as Class II. 
24 4) Removal of planktonic bacteria: $3 \mathrm{~h}$ after bacterial inoculation, the planktonic bacteria are removed leaving only the adhered bacteria to form biofilm. For this, repeat the anesthesia procedure as above. Insert a Huber needle attached to a $1 \mathrm{~mL}$ syringe containing $500 \mu \mathrm{L} 1 \mathrm{X}$ PBS and flush $50-100 \mu \mathrm{L}$ in the TIVAP very slowly. Replace the syringe with new $1 \mathrm{~mL}$ syringe to withdraw about $300 \mathrm{uL}$ blood. Remove this syringe with another syringe containing $\sim 250 \mu \mathrm{L}$ heparin $(500 \mathrm{IU} / \mathrm{ml})$ and lock the TIVAP.

Step 5: Post challenge care and monitoring: (TIMING: 30 minutes per rat)

5A) Monitoring Clinical symptoms: Carefully monitor/record weight loss, fever, diet loss or any other abnormal behavior. Any rat with temperature above $39^{\circ} \mathrm{C}+/-0.5$ or below $34^{\circ} \mathrm{C}+/-0.5$ for continuous 3 days must be euthanized. The sick rats must be euthanized.

5B) Bioluminescence for biofilm development and pathogenesis (see Figure 4): Biofilm formation inside the lumen of the TIVAP and associated infection is measured as a function of bioluminescence. Anesthetized rat (either isoflurane or chemical) is transferred to the dark box of IVIS imaging system with a charged coupled device (CCD) camera (Xenogen Corporation, Alameda, CA, USA) for monitoring bioluminescence. Length of exposure can vary depending on the bacteria and the expected infection. The exposure time can vary depending upon bacteria and infection. Normally, 1 minute exposure is sufficient for $E$. coli and $P$. aeruginosa but for $S$. aureus Xen36 exposure can be about 2-4 minutes. Control rats are exposed for the same or more time compared to test rats.

Critical step: Exposing control rat is important to evaluate and measure background coming from different material such as animal feed or reagents used. It is important to use at least 4 control rats per study for statistics.

5C) Blood sampling: Blood sampling can be done on day 4 and day 8 post-infection to monitor the blood stream infection and associated changes in host factors such as cytokine analysis. Blood $(150 \mu \mathrm{L})$ can be drawn either from the caudal (tail) vein or by retro orbital plexus puncture.

5C.1) Tail vein: (TIMING: 10 minutes per rat).

Anesthetize the rat as described above. In case using chemical anesthesia, inject only $200 \mu \mathrm{L}$ intraperitoneally as the procedure takes only 10 minutes for injection. Clean the tail with $70 \%$ ethanol and rub the tail with a sterile gauze pad to remove the dead scales. Approximately $5 \mathrm{~cm}$ above the tail end insert a tuberculin needle and 
slowly pull the blood. Collect the appropriate volume of blood and transfer to a collection tube containing anti-coagulant (for viable bacteria count, estimation of immune cell population) or tube without anti-coagulant (for cytokine analysis). 5C.2) Retro orbital plexus: (TIMING: 10 minutes per rat) Anesthetize the rat as described above. Put the rat on comfortable table. Use a Pasteur sterile pipette to gently and slowly puncturing the orbital plexus. While firmly holding the Pasteur pipette near the sinus, with gentle rotating movements insert the tube through the membrane. Keep rotating the tube through the orbit until the blood starts to flow. Collect the appropriate volume of blood and transfer to a collection tube containing anti-coagulant (for viable bacteria count, estimation of immune cell population) or tube without anti-coagulant (for cytokine analysis).

Critical Step: Of the circulating blood volume, approximately $10 \%$ of the total volume can be safely removed every 2 to 4 weeks, $7.5 \%$ every 7 days, and $1 \%$ every 24 hours ${ }^{39,40}$.

CAUTION: Technical expertise is required before performing blood sampling. Regarding the presence of retro orbital plexus instead of sinus in rats, it is not a preferred method and a minimum of 10 days must be allowed for tissue repair before repeat sampling from

Step 6: Euthanasia and sampling: (TIMING $\sim 45$ minutes per rat)

After the last day of observation by bioluminescence:

6A) Euthanasia: (TIMING $\sim 5$ minutes per rat)

Euthanize the animals using a procedure validated by the ethics committee of your institution $\left(\mathrm{CO}_{2}\right.$ or chemical euthanasia using IP injection of Dolethal $(2 \mathrm{~mL} / \mathrm{rat}$, $200 \mathrm{mg} / \mathrm{mL}$ )). Put the unconscious rat on a sterile sheet in the laminar air flow system. Clean the body of the rat with $70 \%$ ethanol.

\section{B) Blood sampling on animals: (TIMING: $\sim 5$ min per rat)}

Using a procedure validated by the ethics committee of your institution (retro-orbital plexus/heart puncture/tail vein). The blood (volume depends on experiment planned; $100 \mu \mathrm{L}$ for $\mathrm{CFU} / \mathrm{mL}$ or $200 \mu \mathrm{L}$ for cytokine analysis) is withdrawn by heart puncture. Keep the anesthetized rat on its back on a sterile champ. Feel the heartbeat with your figure for place with fastest beat. Insert at this point a $22 \mathrm{G}$ needle connected to a $1 \mathrm{~mL}$ syringe. Withdraw the blood slowly and transfer to a collection tube containing anti-coagulant (for viable bacteria count, estimation of immune cell population) or tube without anticoagulant (for cytokine analysis).

36 Critical Step: When blood sampling is desired, take the blood sample from rat while it is 
1 due to lack of pumping. Euthanasia by Dolethal takes $\sim 10$ minutes providing 2 experimenter ample of time to sample blood. In case of euthanasia by $\mathrm{CO}_{2}$, first anesthetize rat using $400 \mu \mathrm{L}$ ketamine-xylazine-acepromazine mixture to sample blood.

6C) Organ and TIVAP sampling: (TIMING: 10 min per rat) Aseptical removal of each TIVAP and placement in a sterile Petri plate for imaging with CCD camera imaging system. A set of TIVAPs can be set aside for electron microscopy imaging (see Figure 5). 6C.1) Remove the TIVAP aseptically and put it in a labeled sterile Petri plate.

6D) Organ treatment and enumeration of bacterial load: (TIMING: 10-15 min per rat)

All the procedure is done under the laminar air flow (P2 lab). 6C.2) Aseptically remove spleen, kidneys, lungs, liver and heart and transfer to Petri plates.

6C.3) All organs and TIVAP are imaged using CCD camera for bioluminescence signals.

6D.1) After bioluminescence imaging, wash organs in $4 \mathrm{~mL} 1 \mathrm{X}$ PBS buffer (in a $50 \mathrm{~mL}$ conical tube) before transferring to gentleMACS ${ }^{\mathrm{TM}} \mathrm{M}$ tubes containing $5 \mathrm{~mL} 1 \mathrm{X}$ PBS. 6D.2) Weigh all the organs for analyzing parameters per gram of organ. 6D.3) Homogenize the organs using gentleMACS ${ }^{\mathrm{TM}} M$ tubes with the gentleMACS ${ }^{\mathrm{TM}}$ Octo Dissociator (Miltenyi Biotec). Alternatively, homogenization of each organ can be done using a T25 digital ULTRA-TURRAX ${ }^{\circledR}$ homogenizer (Ika).

6E) Extraction and quantification of biofilm bacteria from TIVAP: (TIMING: 10-15 min per rat) All the procedure is done under the laminar air flow (P2 lab).

$6 \mathrm{E} .1)$ TIVAP are carefully wiped with $70 \% \mathrm{EtOH}$ before extracting intraluminal biofilm bacteria to avoid contaminant.

6E.2) The catheter is cut into small pieces and a slit is made horizontally to expose the lumen and transferred to a microtube containing $1 \mathrm{~mL} 1 \mathrm{X}$ PBS.

6E.3) The septum is removed from the port using a sterile scalpel and forceps, cut into small pieces and transferred to a separate tube containing $1 \mathrm{~mL} 1 \mathrm{X}$ PBS.

6E.4) Cells attached to the titanium body of the port are scratched in $100 \mathrm{~mL} 1 \mathrm{X}$ PBS and transferred to the same tube as the septum. 
6E.5) Biofilm that formed on the septum and in the lumen of catheter is extracted by vigorously vortexing the tubes for $1 \mathrm{~min}$, followed by transferring them to an ultrasonic water bath (NEYtech Ultrasonik, 44-48 Khz) for $5 \mathrm{~min}$ and a second vortexing for 1 minute.

6E.6) The bacterial suspension is then diluted serially, plated on agar plates and incubated at $37^{\circ} \mathrm{C}$ for colony counts. $\mathrm{CFU} / \mathrm{mL}$ and bioluminescent signals (ROI, $\mathrm{p} / \mathrm{S} / \mathrm{cm}^{2} / \mathrm{sr}$ ) are plotted together for correlation.

\section{Other related procedures}

supp1) Port pocket infection: (TIMING $\sim 20$ min per rat)

supp1A) Any inflammation around the port after injecting the bacterial inoculum in the port indicates a pocket infection. supp1B) From euthanized rat, carefully remove the port from the pocket by opening the incision made at the time of surgery. Cut the sutures used for securing the port in the pocket.

supp1C) Image the rat in the dark box of IVIS imaging system with a charged coupled device (CCD) camera (Xenogen Corporation, Alameda, CA, USA) for monitoring bioluminescence and evaluate the bacterial load in the pocket. supp1D) Remove all the pus formed in the pocket for CFU estimation. supp1E) Plate the serial dilutions for $E$. coli and $P$. aeruginosa on LB and for $S$. aureus on TSB.

supp2) Hematogenous infection: (TIMING 10 min per rat)

supp2A) S. aureus Xen36 is used to check the possibility of TIVAP colonization through the venous system. supp2B) Overnight grown S. aureus Xen36 culture is used as inoculum. An inoculum of $5 \times 10^{8}$ cells of $S$. aureus Xen36 is centrifuged, washed and resuspended in $500 \mu \mathrm{L} 1 \mathrm{X}$ PBS. supp2C) Anesthetize the rat as described above. In case using chemical anesthesia, inject only $200 \mu \mathrm{L}$ intraperitoneally as the procedure takes only 10 minutes for injection. supp2D) Clean the tail with $70 \%$ ethanol and rub the tail with a sterile cotton swab to remove the dead scales. Approximately $5 \mathrm{~cm}$ above the tail end, inject bacteria into the bloodstream of rat (already containing implanted TIVAP) through the lateral tail vein. supp2E) Monitor rat before and after injecting bacteria for bioluminescence using IVIS100 imaging system to check infection and colonization. 
supp2G) TIVAP is removed aseptically to confirm the colonization by bioluminescence and plating $\mathrm{CFU} / \mathrm{mL}$. supp2H) 1-cm tip of the catheter is plated for CFU enumeration as the bacteria colonized only the tip of catheter.

supp3) Immunosuppression of rats: (TIMING 15-20 min per rat)

supp3A) Rats are injected intraperitoneally with cyclophosphamide.

CAUTION: cyclophosphamide is toxic and immunosuppressant. Cyclophosphamide is an antineoplastic (anti-cancer) drug categorized as an alkylating agent. Its side effects depend upon dosage such as lowered blood counts, sterility in males and females, pregnancy defects and or discoloration of skin and nails. Using the chemical hood and gloves is highly recommended when using this compound. For detailed literature on side effects, consult: http://www.ncbi.nlm.nih.gov/pubmed/?term=Cyclophosphamide+side+effects supp3B) Dose and regimen of cyclophosphamide delivery are optimized by estimating blood total leukocyte count as determined using an animal blood cell counter (Vet abc, SCIL, Germany $A B C$ vet 2.0, Germany). Furthermore, immunosuppressed status of rats is indicated by the physical state of rats such as lack of appetite, reduced weight and loss of hair. One hundred $\mathrm{mg} / \mathrm{kg}$ body weight of cyclophosphamide was finally selected for giving intraperitoneal injections to rats ( $\mathrm{n}=4$ for each bacterial strain) on day -4 and $50 \mathrm{mg} / \mathrm{kg}$ on day -1 of inoculation.

21 Critical step: An optimized inoculum dose of $10^{2} \mathrm{CFU} / 50 \mu \mathrm{L} 1 \mathrm{X}$ PBS for all bacterial strains (higher inoculum doses lead to the death of animals overnight) is used for TIVAP contamination and is confirmed by plating for $\mathrm{CFU} / \mathrm{mL}$. Control catheterized and immunosuppressed rats receive 50 $\mu$ L 1 X PBS only. supp3C) Prior to inoculation of clinical strains, all rats are checked for the absence of infections as for immune-competent rats.

4) Electron microscopy: (TIMING 30 min per rat)

4A) After aseptic removal of colonized TIVAP from rats, $1 \mathrm{~cm}$ catheter of the catheter tip is cut and the septum is dissected from the port using a scalpel.

4B) Septum and catheter pieces are washed twice in cacodylate solution prepared with gloves and under a chemical hood (0.07 M: $10.5 \mathrm{~mL} 0.2 \mathrm{M}$ Na-cacodylate $\mathrm{pH} 7.4+19.5 \mathrm{~mL}$ sterile $D / W$ ) and then fixed in EM fixative solution (for example, a mixture $\mathrm{v} / \mathrm{v} / \mathrm{v}$ of $6 \%$ glutaraldehyde, $0.15 \%$ Ruthenium red, 0.2M Na-cacodylate $\mathrm{pH} 7.4$ ). 
1 CAUTION: Na-Cacodylate is a derivative of arsenic. It is highly toxic when inhaled, ingested,

2 or put in contact with skin or eyes. It is described as a possible carcinogen and teratogen.

3 Using the chemical hood and gloves is highly recommended when using this compound.

4

4C) Inner lumen of the catheter and face of the septum inside the port are used to visualize biofilm formation.

4D) Samples are stored at $4^{\circ} \mathrm{C}$ until sent for microscopy to the core facility / experts (not more than 10 days).

\section{5) In vivo lock therapy :}

Antibiotics and their concentration for lock therapy studies were chosen based on recommendations made by IDSA guidelines ${ }^{4}$ (Table 1). Efficacy of cefazolin $(5,000 \mathrm{mg} / \mathrm{mL}$ in $5000 \mathrm{IU} / \mathrm{mL}$ heparin) and gentamicin lock therapies $(1.0 \mathrm{mg} / \mathrm{mL}$, or $5 \mathrm{mg} / \mathrm{mL})$, EDTA $(30 \mathrm{mg} / \mathrm{mL})$, ethanol $(70 \%)$, L-arginine $(0.4 \%)$ alone or in combination is evaluated against bioluminescent $E$. coli 55989, $P$. aeruginosa PAK, MSSA S. aureus Xen36, MRSA S. aureus Xen30 and $S$. epidermidis Xen43 ${ }^{27,28,30}$. Since $30 \%$ mortality was observed associated with antibiotic lock therapy ${ }^{27}$, this therapy is always used in conjunction with systemic vancomycin hydrochloride $(50 \mathrm{mg} / \mathrm{kg}$, for MSSA, MRSA, and S. epidermidis) or gentamicin (30 mg/kg, for Gram-negative bacteria) subcutaneous injections ${ }^{42,43}$. The 4-day-old biofilm formed inside the implanted TIVAP is locked $(200 \mu \mathrm{L})$ with the above-discussed antibiotics and monitored for biofilm clearance by measuring bioluminescence. Two types of regimen are followed for lock therapy: first is a 5-day lock regimen during which the old lock is replaced by a new one every $24 \mathrm{~h}$ for 5 days in conjunction with systemic treatment for 5 days. We also assess 1 day lock regimen with a single instillation dwelling for 7 days in conjunction with 1 day of systemic treatment. Rats with a colonized TIVAP but receiving PBS lock are used as controls.

$5 \mathrm{~A})$ Anesthetize infected rat and measure the bioluminescence as described above after 4 days of infection in TIVAP.

5B) Rat is transferred in the hood for instilling antibiotic solution in the TIVAP. Instill $200 \mu \mathrm{L}$ antibiotic solutions in the port slowly. Vancomycin or gentamicin for Gram positive and Gram negative bacteria respectively is injected intraperitoneally to prevent systemic infection due to flushing of the lock into the blood circulation.

\footnotetext{
5C) Replace the lock every $24 \mathrm{~h}$.
} 
1 Critical step: It is possible that TIVAP may be blocked because of biofilm formation and old 2 lock may not be retrievable. In this case flush the old lock with PBS and then instill the fresh 3 lock in the port.

4

5 5D) Monitor biofilm clearance by bioluminescence imaging every day before replacing the 6 lock.

7

$85 \mathrm{E})$ Euthanize rats after day 7 of the last lock instillation for estimating viable cell counts and 9 electron microscopy analyses as described above.

10

11 5F) In case of immunosuppressed rats, they are sacrificed on day 3 post-lock instillation. 12 


\section{TIMING}

2

3 Step1: day -6 to day-1 (6 days)

4 Step2: 1-2 days (step 2A to 2E.19: $\sim 55$ min per rat per day and step2D: could be done in

5 parallel with step $2 \mathrm{~A}$ )

6 Step3: 4 days; $3 \mathrm{~A}$ to $3 \mathrm{C}: \sim 10$ min per rat per day

7 Step 4A to $4 \mathrm{~J}$ : 2 days; $\sim 30$ min per rat (Inoculum is started a day before the challenge)

8 Step A to $5 \mathrm{C} \sim 30$ min per rat.

9 Step 5C.1/5C.2: 10 min per rat

10 Step $6 \mathrm{~A}$ to $6 \mathrm{E} \sim 45$ min per rat 


\begin{tabular}{|c|c|c|c|}
\hline Step & Trouble/problem & Possible reason(s) & Solution \\
\hline $2 \mathrm{E} .14$ & $\begin{array}{l}\text { Catheter blocked } \\
\text { while inserting } \\
\text { inside the vein. }\end{array}$ & $\begin{array}{l}\text { Catheter pushed into } \\
\text { the wrong direction } \\
\text { and entering the right } \\
\text { axillary vein. }\end{array}$ & $\begin{array}{l}\text { Pull the catheter out slightly } \\
\text { and gently rotate it while inside } \\
\text { the jugular vein. Push the } \\
\text { catheter gently in the right } \\
\text { direction. }\end{array}$ \\
\hline $2 \mathrm{E} .15$ & $\begin{array}{l}\text { No Blood reflux } \\
\text { during surgery. }\end{array}$ & $\begin{array}{l}\text { a) Catheter too long } \\
\text { or too short. Catheter } \\
\text { length is optimized to } \\
\text { be } \sim 4.5 \mathrm{~cm} \text { to reach } \\
\text { exactly the tip of the } \\
\text { right atrium. Longer } \\
\text { catheter will reach } \\
\text { inferior vena cava or } \\
\text { enter the rat's heart. } \\
\text { b) The slanting cut } \\
\text { made for inserting } \\
\text { the catheter has } \\
\text { bigger angle. Too } \\
\text { slant cut will result in } \\
\text { pulling the vein } \\
\text { against it due to } \\
\text { pressure and thus } \\
\text { blocking the blood } \\
\text { draw. }\end{array}$ & $\begin{array}{l}\text { a) Pull the catheter out of the } \\
\text { vein slowly. Press the vein with } \\
\text { a wet gauze pad to prevent } \\
\text { blood loss and prevent the } \\
\text { hydration of vein. Check the } \\
\text { length of the catheter and cut it } \\
\text { to the right length. } \\
\text { If the catheter is shorter, than } \\
\text { try to change the position of } \\
\text { the port so that some length } \\
\text { can be gained by reducing the } \\
\text { distance between the port and } \\
\text { the vein (in this case one may } \\
\text { have to optimize the dead } \\
\text { volume to avoid flushing of } \\
\text { bacteria into the blood stream } \\
\text { at the time of challenge). } \\
\text { b) Pull out the catheter as } \\
\text { above and make the right cut } \\
\text { and reinsert it. }\end{array}$ \\
\hline 3B.8 & $\begin{array}{l}\text { TIVAP not patent } \\
\text { during post- } \\
\text { surgery } \\
\text { maintenance. }\end{array}$ & $\begin{array}{l}\text { a) The cut made on } \\
\text { the catheter to insert } \\
\text { was too slanting. } \\
\text { b) The catheter } \\
\text { slipped out of the } \\
\text { vein due to loosely } \\
\text { tied thread to secure } \\
\text { it in the vein. } \\
\text { c) Flushing was not } \\
\text { done properly } \\
\text { resulting in blood }\end{array}$ & $\begin{array}{l}\text { a) Normally, it is not advisable } \\
\text { to make a bigger slant for the } \\
\text { ease of insertion but one can } \\
\text { try to lift the rats from the back } \\
\text { slight to open the channel or } \\
\text { try to gently and slightly move } \\
\text { the catheter without pulling it } \\
\text { out of the vein. } \\
\text { b) If the catheter has slipped } \\
\text { out of the vein, rat must be } \\
\text { excluded from the study. }\end{array}$ \\
\hline
\end{tabular}




\begin{tabular}{|c|c|c|c|}
\hline & & $\begin{array}{l}\text { clotting inside the } \\
\text { TIVAP. }\end{array}$ & $\begin{array}{l}\text { c) These catheters (rats) are } \\
\text { unusable for the study unless } \\
\text { until comparing coating } \\
\text { materials for patency. }\end{array}$ \\
\hline $3 C$ & $\begin{array}{l}\text { Local inflammation } \\
\text { at the site of port } \\
\text { implantation after } \\
\text { surgery. }\end{array}$ & $\begin{array}{l}\text { a) Incision too deep } \\
\text { b) Too much injury to } \\
\text { the port area }\end{array}$ & $\begin{array}{l}\text { a) Only } 1-2 \mathrm{~cm} \text { incision should } \\
\text { be made. Pulling the skin } \\
\text { outwards while making the } \\
\text { incision prevents deep } \\
\text { incisions. } \\
\text { b) Training is required to keep } \\
\text { the injuries to minimum. }\end{array}$ \\
\hline $5 \mathrm{~B}$ & $\begin{array}{l}\text { No signals after } \\
\text { infection. }\end{array}$ & $\begin{array}{l}\text { a) Acquisition time } \\
\text { was short } \\
\text { b) Biofilm formed is } \\
\text { not enough to } \\
\text { capture the signals. } \\
\text { c) Bioluminescence } \\
\text { produced by the } \\
\text { strain used is too } \\
\text { low. }\end{array}$ & $\begin{array}{l}\text { a) Increase the time of } \\
\text { acquisition up to } 4 \text { minutes. In } \\
\text { this case acquire the } \\
\text { bioluminescence for control } \\
\text { rats also for longer time to } \\
\text { avoid background. } \\
\text { b) Biofilm capacities of } \\
\text { different species and strains } \\
\text { can vary. Detailed } \\
\text { characterization of in vitro } \\
\text { biofilm capacities can be } \\
\text { performed. Time for } \\
\text { bioluminescence acquisition } \\
\text { can be adapted to in vitro } \\
\text { biofilm capacities. } \\
\text { c) The bioluminescence signal } \\
\text { produced by bacteria must be } \\
\text { high in order to be visible } \\
\text { through the skin of the rat and } \\
\text { through the TIVAP. } \\
\text { Measurement } \\
\text { bioluminescence during in vitro } \\
\text { biofilm formation within TIVAP } \\
\text { can be performed to ensure } \\
\text { that it is strong enough to be } \\
\text { detected. }\end{array}$ \\
\hline 6E.6 & $\begin{array}{l}\text { No biofilm } \\
\text { formation at the }\end{array}$ & $\begin{array}{l}\text { a) Bacterial inoculum } \\
\text { may not be enough }\end{array}$ & $\begin{array}{l}\text { a) Bacterial inoculum } \\
\text { optimization maybe needed for }\end{array}$ \\
\hline
\end{tabular}




\begin{tabular}{|l|l|l|l|}
\hline end of the study. & $\begin{array}{l}\text { to form biofilm } \\
\text { b) Time required for } \\
\text { bacteria to adhere } \\
\text { maybe longer. }\end{array}$ & $\begin{array}{l}\text { your bacterial strains. } \\
\text { b) Increase the time to remove } \\
\text { planktonic bacteria after } \\
\text { injecting inoculum. } \\
\text { c) Different catheters } \\
\text { may behave properties may } \\
\text { differently. } \\
\text { d) Contamination on } \\
\text { the catheters can } \\
\text { prevent biofilm } \\
\text { formation. }\end{array}$ & $\begin{array}{l}\text { dry changing the lot used. } \\
\text { d) Contamination from the rat } \\
\text { flora can prevent biofilm } \\
\text { formation of your strain. } \\
\text { Disinfect the skin of the rat } \\
\text { properly to avoid any external } \\
\text { contamination. }\end{array}$ \\
\hline
\end{tabular}

2 Table 2. TROUBLE SHOOTING

3

4 


\section{ANTICIPATED RESULTS}

3 1. Luminescent signals corresponding to bacterial colonization can be measured 4 within $3 \mathrm{~h}$ after the injection of inoculum for $E$. coli and $P$. aeruginosa. For $S$. aureus, the luminescent signal can be measured after $24 \mathrm{~h}$. Exposure time to measure the luminescence can vary between bacterial strains. Normally, $1 \mathrm{~min}$ of exposure is sufficient to detect measurable signals for bioluminescent variant strains (used in the study) of $E$. coli 55989 and $P$. aeruginosa PAK but one can expect an exposure time of 2-4 minutes for $S$. aureus Xen36 ${ }^{27}$. For $S$. epidermidis Xen43 bioluminescence signals were not obtained for any concentration of inoculum. One can expect to harvest $\sim 7.6$ to 8.3-log CFU/mL (port) and $\sim 7.5$ to 9.2-log CFU/mL (catheter) of biofilm biomass from TIVAP after $10 \mathrm{~d}$ of infection. Increase in biofilm-associated bioluminescence could be measured up to day 120 post-infection with signals reaching maximum on day 4 . Reduced signals were observed from day 8 onwards, indicating restriction of biofilms to TIVAP colonization (Figure 5) ${ }^{27}$. These results can be correlated to the bloodstream infection as indicated by presence of bacteria on day 4 whereas clearance of bacteria from the peripheral blood by day 8 . Thus, this model allows non-invasive study of chronic biofilm infection.

2. In case of immunosuppressed rats, severe pathology can be seen as indicated by weight loss, fever and high bioluminescence as function of systemic biofilm infection leading to death of animals by day 3 (Figure 6) ${ }^{27}$. The blood and organ samples show high bacterial load compared to immune-competent rats.

3. In case of lock therapy experiments, the absence of bioluminescence may be observed just after 1 instillation of antibiotic solution, such as in case of gentamicin+EDTA lock. On contrary, this bioluminescence signals indicating presence of persistent bacteria in the catheter may be seen as in case of gentamicin, EDTA, Larginine alone (Figure 7) ${ }^{28}$. Lock therapy may lead to bloodstream and systemic infection in some rats. Thus, use of systemic treatment in conjunction with lock therapy is required.

4. In addition to biofilm pathogenesis, molecular mechanisms associated with biofilm can be studied ${ }^{29}$. It was shown using mutants of a bioluminescent variant of $E$. coli 55989 that lipid A palmitoylation did not affect the bacterial adherence to catheters but enhanced the in vivo biofilm survival. Moreover, the palmitoylation lead to reduced 
1 cytokine trigger in vivo in rat model indicating role of palmitoylation in evading host 2 defenses ${ }^{29}$.

3

4 5. Modified TIVAP coated with methylcellulose and PEG was used to evaluate 5 prevention of adhesion of $P$. aeruginosa and $S$. aureus using the rat model and thus, 6 biofilm inhibition (Figure 8$)^{26}$.

7 
1

\begin{tabular}{|c|c|c|c|c|c|c|}
\hline Microorganism & $\begin{array}{l}\text { Gentamicin } \\
(30 \mathrm{mg} / \mathrm{mL})\end{array}$ & $\begin{array}{l}\text { Cefazolin } \\
(5 \mathrm{mg} / \mathrm{mL})\end{array}$ & $\begin{array}{c}\text { EDTA } \\
(30 \mathrm{mg} / \mathrm{mL})\end{array}$ & $\begin{array}{c}\text { Ethanol } \\
(70 \%)\end{array}$ & $\begin{array}{l}\text { Gentamicine+EDTA } \\
(5 \mathrm{mg} / \mathrm{mL}+30 \mathrm{mg} / \mathrm{mL})\end{array}$ & $\begin{array}{c}\text { Gentamicine } \\
+ \text { Cefazolin } \\
(1 \mathrm{mg} / \mathrm{mL}+5 \mathrm{mg} / \mathrm{mL})\end{array}$ \\
\hline E. coli & $\mathrm{Y}$ & N.D. & $\mathrm{Y}$ & N.D. & $\bar{Y}$ & N.D. \\
\hline$P$. aeruginosa & $\mathrm{Y}$ & N.D. & $\mathrm{Y}$ & N.D. & $\mathrm{Y}$ & N.D. \\
\hline MSSA & N.D. & $\mathrm{Y}$ & $\mathrm{Y}$ & $\mathrm{Y}$ & $\mathrm{Y}$ & $\mathrm{Y}$ \\
\hline MRSA & N.D. & N.D. & $\mathrm{Y}$ & N.D. & $\mathrm{Y}$ & N.D. \\
\hline S. epidermidis & N.D. & N.D. & $\mathrm{Y}$ & N.D. & $\mathrm{Y}$ & N.D. \\
\hline
\end{tabular}

2 Y: Efficacy tested, N.D.: efficacy not tested

3 Table 1: Lock therapy concentration $(\mathrm{mg} / \mathrm{mL})$ 
Figure 1. Schematic representation of the different steps of the in vivo model of totally implantable venous access port related infection. Steps in black boxes correspond to regular procedures of implantation, contamination and monitoring of colonization. Steps in yellow boxes correspond to potential procedures that can be applied to the regular model.

Figure 2. TIVAP surgical implantation. TIVAP were surgically implanted in CD/SD (IGS: Crl) rats. Surgery was performed under laminar air flow using a surgical hood and aseptic conditions were maintained throughout the surgical procedure. For ease, labels in figure correspond to steps described in the procedure under surgery section. (2A) Rat was briefly kept in an isoflurane box to calm down and injected intraperitoneally with a chemical anesthesia mixture to complete sedation and analgesia before starting the procedure. (2B.1 - 2B.2) Rat was shaved on dorsal side from the neck to the lower end of thoracic vertebrae and along the neck line of ventral side. (2C) Disinfection of skin using betadine soap and solution. (2D) Pre-surgical preparations. Instruments and objects required during the surgery kept on a sterile sheet in the laminar air flow. (2E.2) Incision was made along the dorsal line at the upper thoracic vertebrae. (2E.4.1 - 2E.4.2 1 - 2E.4.3) TIVAP inserted in the subcutaneous pocket and secured by sutures. (2E.5.1) Huber needle inserted in the port. (2E.5.2) Rat flipped on its back. (2E.6) $1-1.5 \mathrm{~cm}$ Incision in neck region (2E.7.1 - 2E.7.2) Jugular vein exposed. Work on animals was performed in compliance with French and European regulations on care and protection of laboratory animals (European Commission directive 2010/63; French law 2013-118, 06th February, 2013). The protocols used in this study were approved by the ethics committee of "Paris Centre et Sud N59" (reference 2012-0045).

Figure 3. TIVAP surgical implantation (contd.). (2E.8) Cotton threads inserted under the jugular vein to secure catheter. (2E.10) Tunneling rod inserted for passing the catheter under the skin from dorsal to ventral side. (2E.11) Catheter cut at a slant (inside caption showing the correct cut). (2E.13) Jugular vein incised using micro spring scissors. (2E.14) Dilation of jugular vein using forceps. (2E.14.1 to 2E.14. 5) Catheter inserted in the jugular vein. (2E.15) Flush and draw blood to check patency of TIVAP. (2E.17.1 - 2E.17.2) Surgical wounds closed by suturing ventral and dorsal incisions. Work on animals was performed in compliance with French and European regulations on care and protection of laboratory animals (European Commission directive 2010/63; 
1 French law 2013-118, 06th February, 2013). The protocols used in this study were approved by the ethics committee of "Paris Centre et Sud N59" (reference 2012-0045).

Figure 4: Bacterial inoculation and monitoring of biofilm formation using bioluminescence. The bacterial inoculum is directly injected through the septum of the TIVAP using a Huber needle and biofilm development is monitored using a CCD camera imaging system allowing to measure bioluminescence. Below is shown an example of the images obtained for the colonization of the TIVAP by a bioluminescent clinically relevant strain of $P$.aeruginosa and showing the progressive biofilm development within the TIVAP. Work on animals was performed in compliance with French and European regulations on care and protection of laboratory animals (European Commission directive 2010/63; French law 2013-118, 06th February, 2013). The protocols used in this study were approved by the ethics committee of "Paris Centre et Sud N ${ }^{\circ} 59^{\prime}$ (reference 2012-0045).

Figure 5. Biofilm formation in TIVAP was confirmed by scanning electron microscopy (SEM). TIVAPs implanted in rats and inoculated with $S$. aureus, $P$. aeruginosa or $E$. coli were harvest on day 5 post-infection and analyzed with scanning electron microscopy. Arrows represent bacteria in biofilm; arrowheads, blood cells. (A) TIVAP inoculated with $S$. aureus, (B) TIVAP inoculated with $P$. aeruginosa, (C) TIVAP inoculated with E. coli. (E) Scanning electron microscopy to show $P$. aeruginosa biofilm growing inside the lumen of implanted catheter with typical biofilm micro colonies. (F-G) Magnified view: a $P$. aeruginosa micro colony showing typical biofilm structures. Work on animals was performed in compliance with French and European regulations on care and protection of laboratory animals (European Commission directive 2010/63; French law 2013-118, 06th February, 2013). The protocols used in this study were approved by the ethics committee of "Paris Centre et Sud N59" (reference 2012-0045).

Figure 6. Biofilm led to lethal infection in immunosuppressed rats. (A) TIVAP implanted and cyclophosphamide-treated rats were injected with $10^{2} \mathrm{CFU}$ in $100 \mathrm{~mL}$ of $P$. aeruginosa into the port of TIVAP and photon emission was monitored up to day 3 to evaluate biofilm formation and associated infection.

(B) Bacterial load from different organs aseptically removed from dead animals was analyzed, organs were homogenized and were plated on LB agar for viable counts per $\mathrm{mL}$. CFU results are means +/- standard deviations. Number of rats $(n)$ used in the experiment, $n=4$. Work 
and protection of laboratory animals (European Commission directive 2010/63; French law 2013-118, 06th February, 2013). The protocols used in this study were approved by the ethics committee of "Paris Centre et Sud N59" (reference 2012-0045).

Figure 7. In vivo lock therapy against Staphylococcus aureus biofilm in the implanted TIVAP: 5-day regimen presented. $200 \mu \mathrm{L}$ high dose antibiotics solution was instilled in TIVAP of rats (day 0 ) to treat methicillin sensitive $S$. aureus biofilm colonization $(n=5)$. Lock therapy was associated with systemic vancomycin for $S$. aureus. The lock was renewed every $24 \mathrm{~h}$ for 5 days, and its efficacy was monitored as photon emissions. (A) Control rats with PBS lock. (B) $5 \mathrm{mg} / \mathrm{mL}$ gentamicin lock. (C) 30 $\mathrm{mg} / \mathrm{mL}$ EDTA alone. (D) Combined gentamicin $(5 \mathrm{mg} / \mathrm{mL})$ and EDTA (30 mg/mL) lock. In panels $A$ to $D$, representative experiments are shown. $(E-H)$ Rats were euthanized after 7 days of treatment, and TIVAP were harvested and monitored for photon emissions. (I) Bacterial cells from TIVAP were harvested and plated on TSB agar for counts of $\mathrm{CFU} / \mathrm{mL}$. CFU results are means +/- standard deviations. One-way analysis of variance (ANOVA) with Graphpad Prism version 5.0c was used for statistical analysis. A $P$ value of $<0.05$ was considered significant, ${ }^{* * * *} P<0.0001$. Work on animals was performed in compliance with French and European regulations on care and protection of laboratory animals (European Commission directive 2010/63; French law 2013-118, 06th February, 2013). The protocols used in this study were approved by the ethics committee of "Paris Centre et Sud N59" (reference 2012-0045).

Figure 8. Modified anti-adhesive totally implantable venous access port (TIVAP).

(A) Commercially available pediatric TIVAP used in the study, and dismantled TIVAP (a, catheter; $b$ and $c$, envelope of port; $d$, sealing ring of port; e, septum; $f$, titanium port) and anti-adhesive molecules used to modify TIVAP parts. The catheter and septum were modified using methylcellulose (MeCe) derivative and the titanium port was modified using polyethylene glycol (PEG) derivative. (B) Rats with modified or unmodified implanted TIVAPs were inoculated with $10^{6}$ colony-forming units (CFUs) of Staphylococcus aureus or $10^{3}$ CFUs of Pseudomonas aeruginosa per $50 \mu \mathrm{L}$ of $1 \mathrm{X}$ phosphate-buffered saline. Bacteria were allowed to adhere to the TIVAP endoluminal surface for 3 hours ( $S$. aureus) or 1.5 hours ( $P$. aeruginosa) and biofilms were left to form for 5 days, and TIVAP was extracted to measure bacterial biofilm colonization.

34 Viable bacteria were counted by plating on tryptic soy agar for $S$. aureus or lysogeny broth agar for $P$. aeruginosa. (Control: unmodified TIVAP and Si-Ti: both silicone and 
1 (ANOVA) with GraphPad Prism software (version 5.0c). Differences were considered 2 significant at $P<0.05$. ${ }^{*} P \leq 0.01$; ${ }^{* *} P \leq 0.001$. Work on animals was performed in 3 compliance with French and European regulations on care and protection of laboratory 4 animals (European Commission directive 2010/63; French law 2013-118, 06th February, 5 2013). The protocols used in this study were approved by the ethics committee of "Paris 6 Centre et Sud N59" (reference 2012-0045). 


\begin{tabular}{|c|c|c|c|}
\hline & Pros of the model & & Cons of the model \\
\hline 1 & Clinically relevant & 1 & Labor intensive \\
\hline 2 & $\begin{array}{l}\text { Only requires basic small animal surgical } \\
\text { training }\end{array}$ & 2 & $\begin{array}{l}\text { Requires a 1-3 month training to } \\
\text { acquire optimal technical expertise }\end{array}$ \\
\hline 3 & $\begin{array}{l}\text { Totally implanted and no requirement for } \\
\text { external containments on the animal }\end{array}$ & 3 & Expensive \\
\hline 4 & $\begin{array}{l}\text { Closed by a septum enabling controlled } \\
\text { infections and reduced external uncontrolled } \\
\text { contaminations }\end{array}$ & 4 & $\begin{array}{l}\text { Require daily manipulation } \\
\text { (flush/draw) to avoid thrombosis and } \\
\text { clogging }\end{array}$ \\
\hline 5 & $\begin{array}{l}\text { Allows the in vivo study of all clinically relevant } \\
\text { catheter pathogens }\end{array}$ & 5 & $\begin{array}{l}\text { Restricted use in rat due to difficulty } \\
\text { to adapt for small-sized mice }\end{array}$ \\
\hline 6 & $\begin{array}{l}\text { Allows in vivo biofilm monitoring over very long } \\
\text { period (model of chronic infection) thus } \\
\text { reducing the number of used animals }\end{array}$ & & \\
\hline 7 & $\begin{array}{l}\text { Biofilm progression can be studied using } \\
\text { luminescent bacteria or fungi (Candida sp.) }\end{array}$ & & \\
\hline 8 & $\begin{array}{l}\text { Allows the evaluation of prophylactic and } \\
\text { curative anti-biofilm approaches }\end{array}$ & & \\
\hline 9 & $\begin{array}{l}\text { Allows the evaluation of the contribution of the } \\
\text { host immune system in biofilm development }\end{array}$ & & \\
\hline
\end{tabular}

2

3 Table 3. Advantages, limitations and adaptations: 


\section{AUTHOR CONTRIBUTIONS STATEMENTS}

2 A.C. and C.B. initiated the development of the model. A.C., JM.G. and C.B. designed the 3 experiments. A.C. performed the experiments. A.C., JM.G. and C.B. wrote the 4 manuscript.

5

6 ACKNOWLEDGMENTS

7 We thank David Lebeaux for critical reading of the manuscript. This work was supported

8 by the French government's Investissement d'Avenir program, Laboratoire d'Excellence

9 "Integrative Biology of Emerging Infectious Diseases" (grant ANR-10-LABX-62-IBEID)

10 and the Fondation pour la "Recherche Médicale grant" (Equipe FRM

11 DEQ20140329508).

12

\section{COMPETING FINANCIAL INTERESTS}

14 The authors declare that they have no competing financial interests. 


\section{REFERENCES}

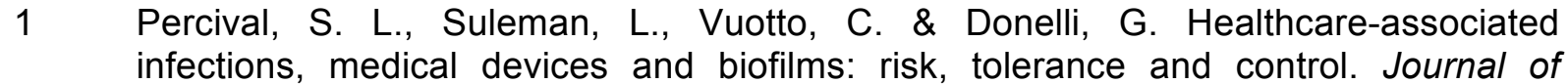
medical microbiology 64, 323-334, doi:10.1099/jmm.0.000032 (2015).

2 Hoiby, N. et al. ESCMID guideline for the diagnosis and treatment of biofilm infections 2014. Clinical microbiology and infection : the official publication of the European Society of Clinical Microbiology and Infectious Diseases 21 Suppl 1, S1-25, doi:10.1016/j.cmi.2014.10.024 (2015).

3 Lebeaux, D. et al. Management of infections related to totally implantable venousaccess ports: challenges and perspectives. The Lancet. Infectious diseases 14, 146159, doi:10.1016/S1473-3099(13)70266-4 (2014).

4 Mermel, L. A. et al. Clinical practice guidelines for the diagnosis and management of intravascular catheter-related infection: 2009 Update by the Infectious Diseases Society of America. Clin Infect Dis 49, 1-45, doi:10.1086/599376 (2009).

5 Bouza, E., Perez-Molina, J. A. \& Munoz, P. Report of ESGNI-001 and ESGN2-002 studies. Bloodstream infections in Europe. Clinical Microbiology and Infection 5, 2S12S12 (1999).

6 Ceri, H. et al. The Calgary Biofilm Device: new technology for rapid determination of antibiotic susceptibilities of bacterial biofilms. J Clin Microbiol 37, 1771-1776 (1999).

7 Coenye, T. \& Nelis, H. J. In vitro and in vivo model systems to study microbial biofilm formation. Journal of microbiological methods 83, 89-105, doi:10.1016/j.mimet.2010.08.018 (2010).

8 Donlan, R. M. et al. Model system for growing and quantifying Streptococcus pneumoniae biofilms in situ and in real time. Applied and Environmental Microbiology 70, 4980-4988, doi:10.1128/AEM.70.8.4980-4988.2004 (2004).

9 Goeres, D. M. et al. Statistical assessment of a laboratory method for growing biofilms. Microbiology 151, 757-762, doi:10.1099/mic.0.27709-0 (2005).

10 Lebeaux, D., Chauhan, A., Rendueles, O. \& Beloin, C. From in vitro to in vivo Models of Bacterial Biofilm-Related Infections. Pathogens 2, 288-356, doi:10.3390/pathogens2020288 (2013).

11 Parra-Ruiz, J., Vidaillac, C., Rose, W. E. \& Rybak, M. J. Activities of high-dose daptomycin, vancomycin, and moxifloxacin alone or in combination with clarithromycin or rifampin in a novel in vitro model of Staphylococcus aureus biofilm. Antimicrobial agents and chemotherapy 54, 4329-4334, doi:10.1128/AAC.00455-10 (2010).

12 Cirioni, O. et al. RNAlll-inhibiting peptide significantly reduces bacterial load and enhances the effect of antibiotics in the treatment of central venous catheterassociated Staphylococcus aureus infections. J Infect Dis 193, 180-186, doi:JID34996 [pii]10.1086/498914 (2006).

$13 \mathrm{Li}, \mathrm{H}$. et al. Conversion of Staphylococcus epidermidis strains from commensal to invasive by expression of the ica locus encoding production of biofilm exopolysaccharide. Infection and immunity 73, 3188-3191, doi:10.1128/IAI.73.5.31883191.2005 (2005).

14 Rupp, M. E., Ulphani, J. S., Fey, P. D. \& Mack, D. Characterization of Staphylococcus epidermidis polysaccharide intercellular adhesin/hemagglutinin in the pathogenesis of intravascular catheter-associated infection in a rat model. Infection and immunity 67, 2656-2659 (1999).

15 Ulphani, J. S. \& Rupp, M. E. Model of Staphylococcus aureus central venous catheter-associated infection in rats. Laboratory animal science 49, 283-287 (1999).

16 Lorenz, U. et al. The alternative sigma factor sigma B of Staphylococcus aureus modulates virulence in experimental central venous catheter-related infections. Microbes and infection / Institut Pasteur 10, 217-223, doi:10.1016/j.micinf.2007.11.006 (2008). 
17 Kokai-Kun, J. F., Chanturiya, T. \& Mond, J. J. Lysostaphin eradicates established Staphylococcus aureus biofilms in jugular vein catheterized mice. J Antimicrob Chemother 64, 94-100, doi:10.1093/jac/dkp145 (2009).

18 Fernandez-Hidalgo, N. et al. Evaluation of linezolid, vancomycin, gentamicin and ciprofloxacin in a rabbit model of antibiotic-lock technique for Staphylococcus aureus catheter-related infection. J Antimicrob Chemother 65, 525-530, doi:dkp499 [pii]10.1093/jac/dkp499 (2010).

19 Andes, D. et al. Development and characterization of an in vivo central venous catheter Candida albicans biofilm model. Infection and immunity 72, 6023-6031, doi:10.1128/IAI.72.10.6023-6031.200472/10/6023 [pii] (2004).

20 Lazzell, A. L. et al. Treatment and prevention of Candida albicans biofilms with caspofungin in a novel central venous catheter murine model of candidiasis. $J$ Antimicrob Chemother 64, 567-570, doi:dkp242 [pii]10.1093/jac/dkp242 (2009).

$21 \mathrm{Li}, \mathrm{F}$. et al. Eap1p, an adhesin that mediates Candida albicans biofilm formation in vitro and in vivo. Eukaryotic cell 6, 931-939, doi:10.1128/EC.00049-07 (2007).

22 Schinabeck, M. K. et al. Rabbit model of Candida albicans biofilm infection: liposomal amphotericin B antifungal lock therapy. Antimicrobial agents and chemotherapy 48 , 1727-1732 (2004).

23 Kadurugamuwa, J. L. et al. Direct continuous method for monitoring biofilm infection in a mouse model. Infection and immunity 71, 882-890 (2003).

24 Vuong, C., Kocianova, S., Yu, J., Kadurugamuwa, J. L. \& Otto, M. Development of real-time in vivo imaging of device-related Staphylococcus epidermidis infection in mice and influence of animal immune status on susceptibility to infection. $J$ Infect Dis 198, 258-261, doi:10.1086/589307 (2008).

25 Wang, R. et al. Staphylococcus epidermidis surfactant peptides promote biofilm maturation and dissemination of biofilm-associated infection in mice. The Journal of clinical investigation 121, 238-248, doi:10.1172/JCI42520 (2011).

26 Chauhan, A. et al. Preventing biofilm formation and associated occlusion by biomimetic glycocalyxlike polymer in central venous catheters. J Infect Dis 210, 13471356, doi:10.1093/infdis/jiu249 (2014).

27 Chauhan, A. et al. A rat model of central venous catheter to study establishment of long-term bacterial biofilm and related acute and chronic infections. PloS one 7, e37281, doi:10.1371/journal.pone.0037281 (2012).

28 Chauhan, A., Lebeaux, D., Ghigo, J. M. \& Beloin, C. Full and broad-spectrum in vivo eradication of catheter-associated biofilms using gentamicin-EDTA antibiotic lock therapy. Antimicrobial agents and chemotherapy 56, 6310-6318, doi:10.1128/AAC.01606-12 (2012).

29 Chalabaev, S. et al. Biofilms formed by gram-negative bacteria undergo increased lipid a palmitoylation, enhancing in vivo survival. mBio 5, doi:10.1128/mBio.01116-14 (2014).

30 Lebeaux, D. et al. $\mathrm{pH}$-mediated potentiation of aminoglycosides kills bacterial persisters and eradicates in vivo biofilms. J Infect Dis 210, 1357-1366, doi:10.1093/infdis/jiu286 (2014).

31 Fatkenheuer, G. et al. Central venous catheter (CVC)-related infections in neutropenic patients--guidelines of the Infectious Diseases Working Party (AGIHO) of the German Society of Hematology and Oncology (DGHO). Annals of hematology 82 Suppl 2, S149-157, doi:10.1007/s00277-003-0769-z (2003).

32 Messing, B., Peitra-Cohen, S., Debure, A., Beliah, M. \& Bernier, J. J. Antibiotic-lock technique: a new approach to optimal therapy for catheter-related sepsis in homeparenteral nutrition patients. JPEN. Journal of parenteral and enteral nutrition 12 , 185-189 (1988).

33 Zeng, G., Ogaki, R. \& Meyer, R. L. Non-proteinaceous bacterial adhesins challenge the antifouling properties of polymer brush coatings. Acta biomaterialia, doi:10.1016/j.actbio.2015.05.037 (2015). 
34 Mussard, W., Kebir, N., Kriegel, I., Esteve, M. \& Semetey, V. Facile and efficient

35 van Rooden, C. J. et al. Infectious complications of central venous catheters increase

36 Ramphal, R. et al. Control of Pseudomonas aeruginosa in the lung requires the recognition of either lipopolysaccharide or flagellin. Journal of immunology 181, 586592 (2008).

37 Bernier, C., Gounon, P. \& Le Bouguenec, C. Identification of an aggregative adhesion fimbria (AAF) type III-encoding operon in enteroaggregative Escherichia coli as a sensitive probe for detecting the AAF-encoding operon family. Infection and immunity 70, 4302-4311 (2002).

38 Foucault, M. L., Thomas, L., Goussard, S., Branchini, B. R. \& Grillot-Courvalin, C. In vivo bioluminescence imaging for the study of intestinal colonization by Escherichia coli in mice. Appl Environ Microbiol 76, 264-274, doi:10.1128/AEM.01686-09 (2010).

39 McGuill, M. W. \& Rowan, A. N. Biological Effects of Blood Loss: Implications for Sampling Volumes and Techniques. ILAR News 31, 5-20 (1989).

40 Removal of blood from laboratory mammals and birds. First report of the BVA/FRAME/RSPCA/UFAW Joint Working Group on Refinement. Laboratory animals 27, 1-22 (1993).

41 van Herck, $\mathrm{H}$. et al. Orbital sinus blood sampling in rats as performed by different animal technicians: the influence of technique and expertise. Laboratory animals $\mathbf{3 2}$, 377-386 (1998).

42 Van Praagh, A. D. et al. Daptomycin antibiotic lock therapy in a rat model of staphylococcal central venous catheter biofilm infections. Antimicrobial agents and chemotherapy 55, 4081-4089, doi:10.1128/AAC.00147-11 (2011).

43 Zuluaga, A. F., Agudelo, M., Cardeno, J. J., Rodriguez, C. A. \& Vesga, O. Determination of therapeutic equivalence of generic products of gentamicin in the neutropenic mouse thigh infection model. PloS one 5, e10744, doi:10.1371/journal.pone.0010744 (2010). 


\section{Protocol overview}

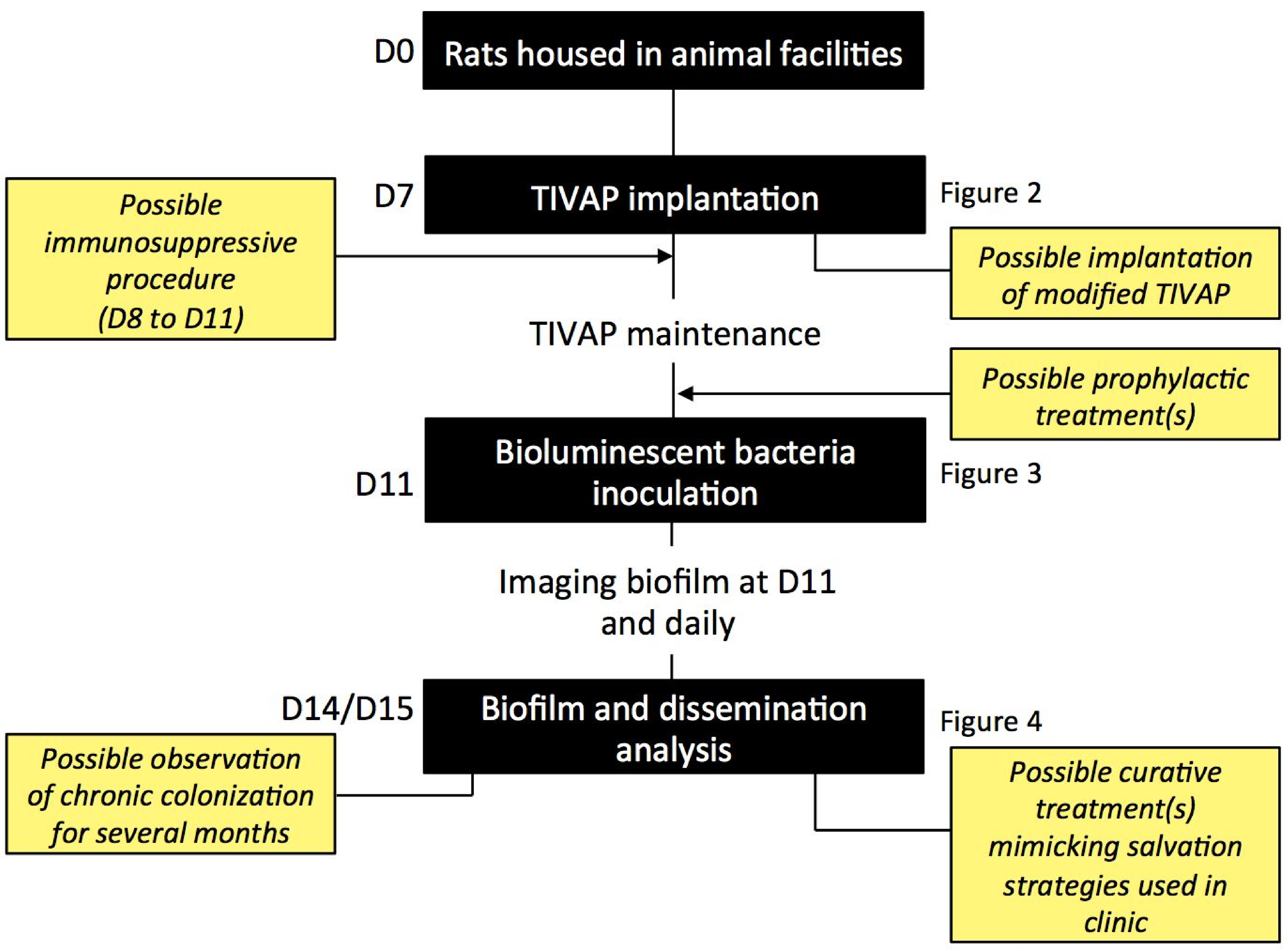

Figure 1 

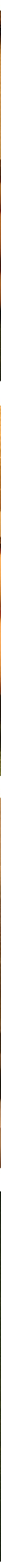

Figure 3 


\section{Controlled Inoculation}

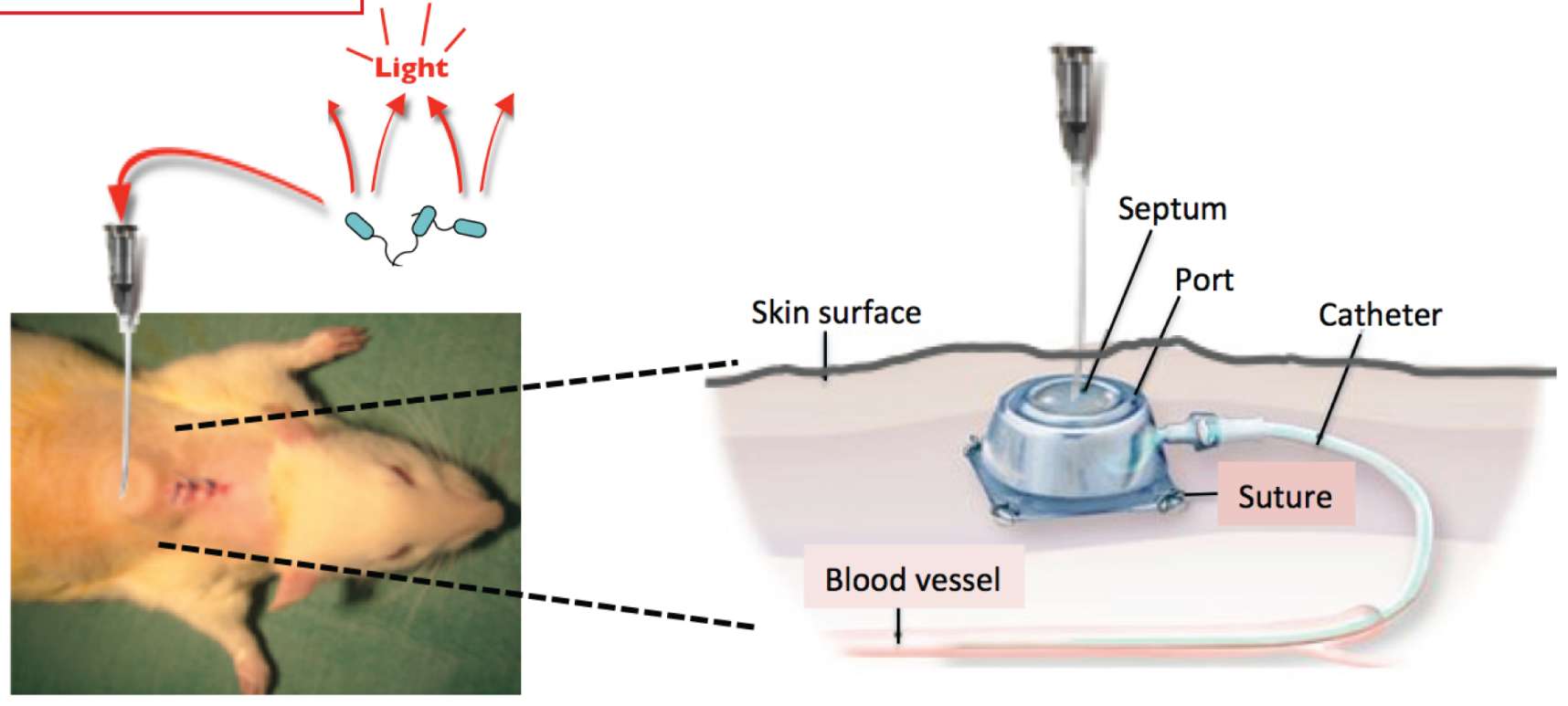

Non invasive in situ monitoring of biofilm development using CCD imaging system

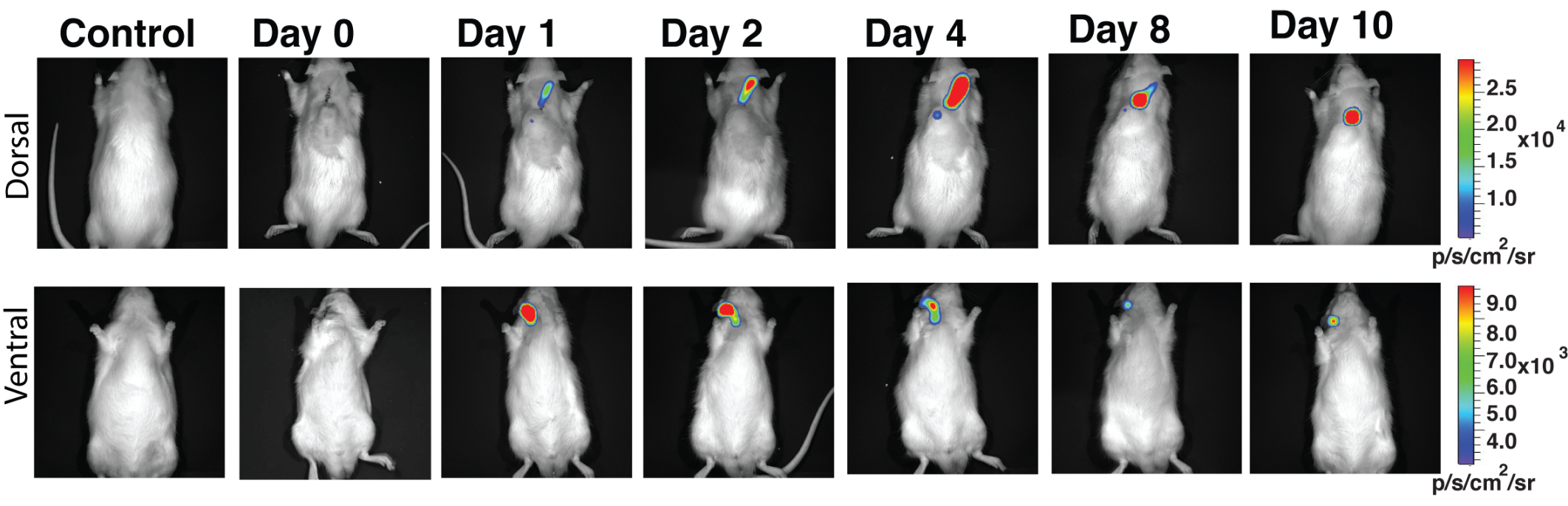

Figure 4 

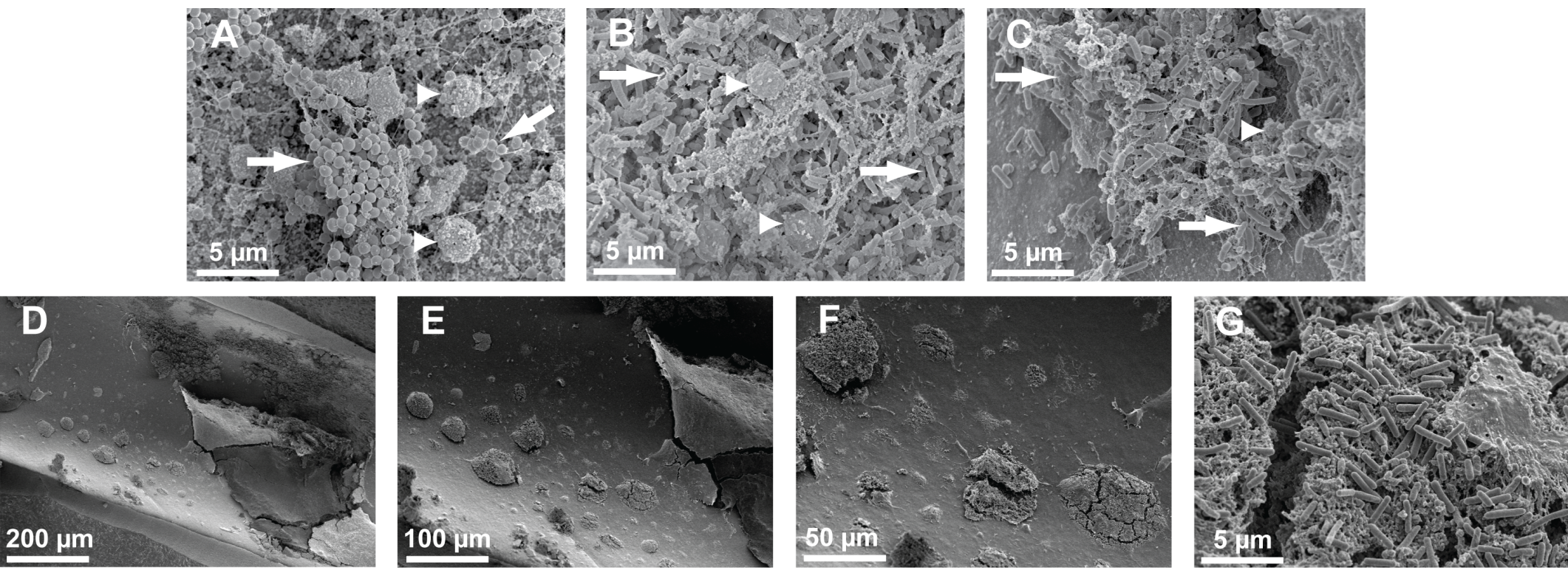

Figure 5 
A

Day 0

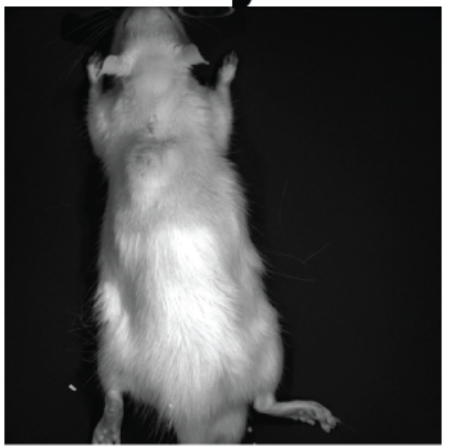

B
Day 1

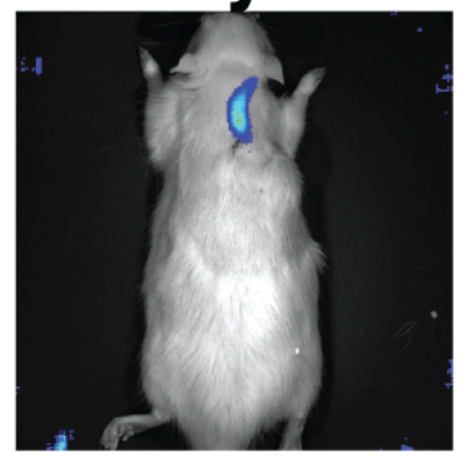

Day 2

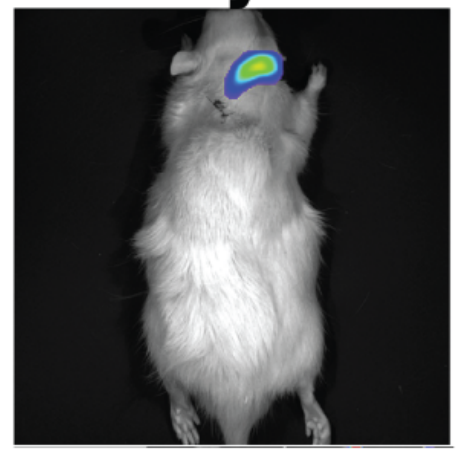

Day 3

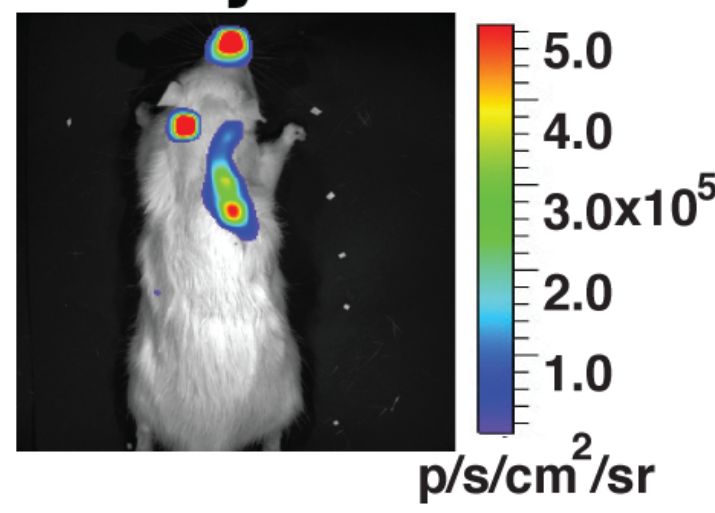

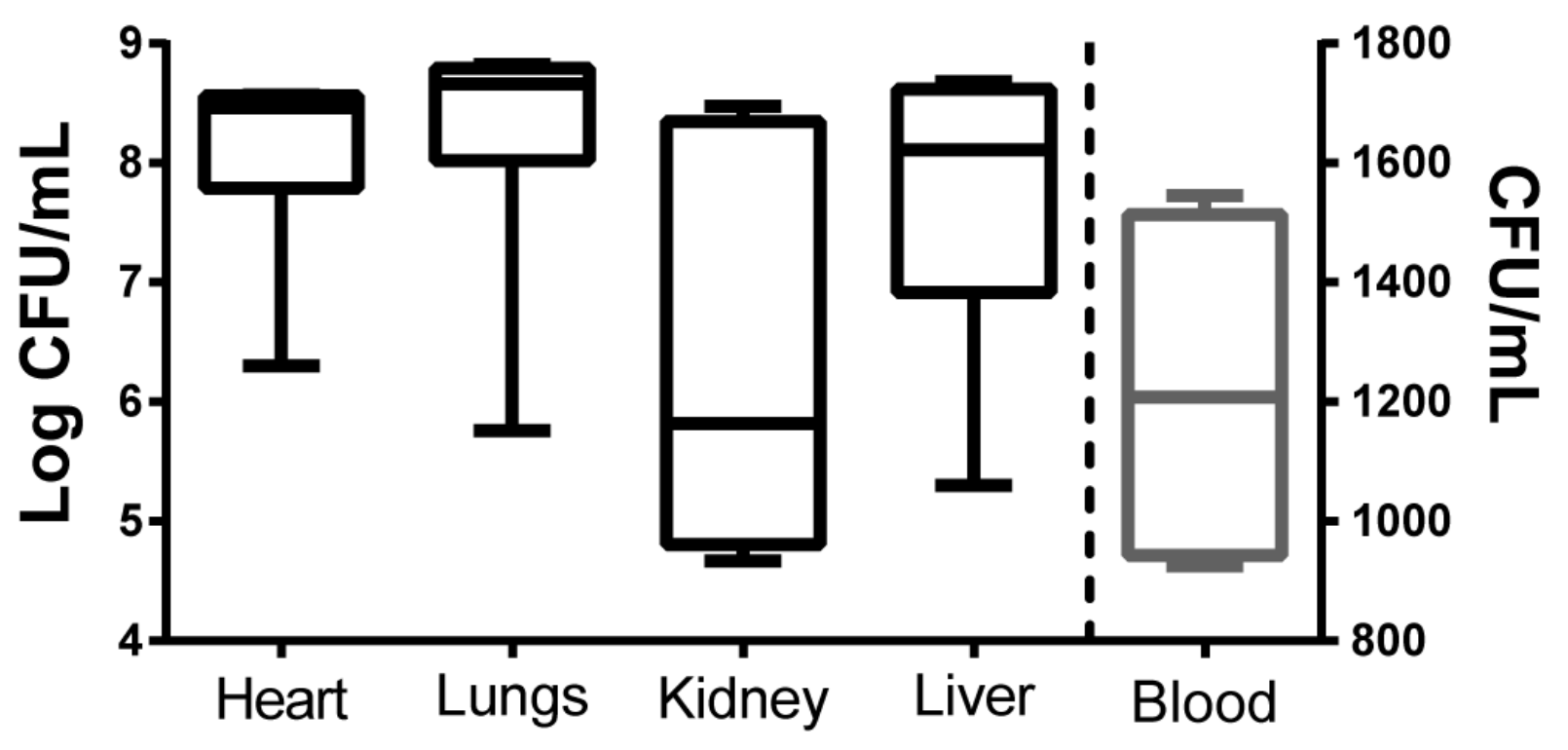

Figure 6 
$\mathbf{A}$
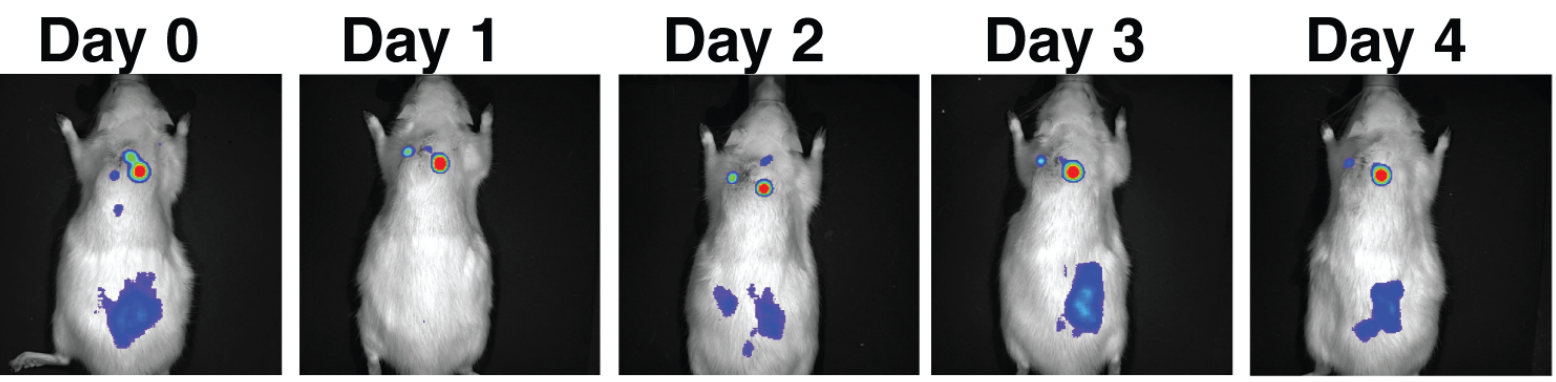

Day 2

Day 3
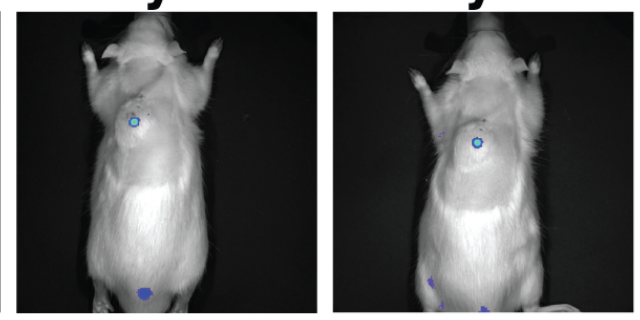

Day 4

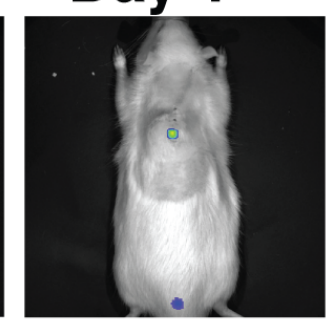

C

\section{Day 0}
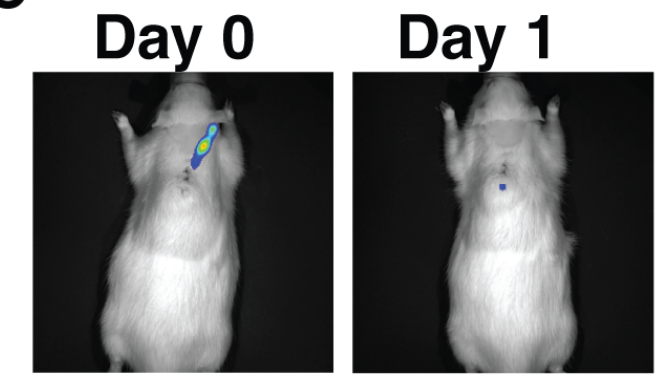

D
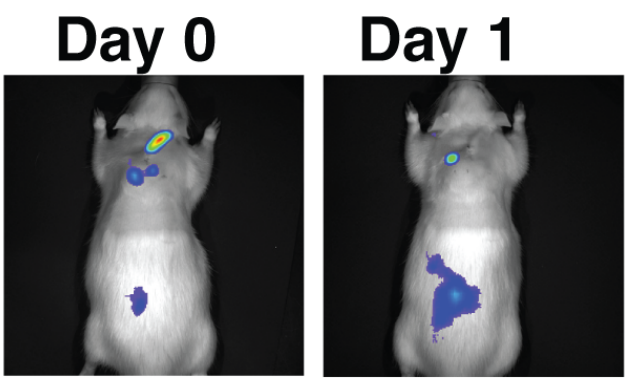

Day 2

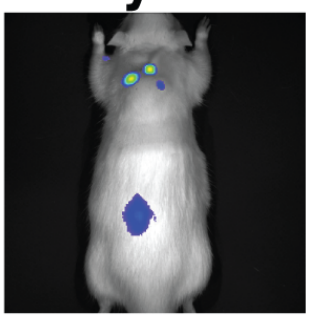

Day 2

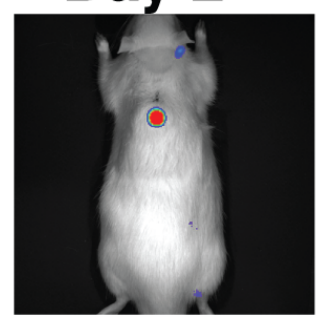

Day 3

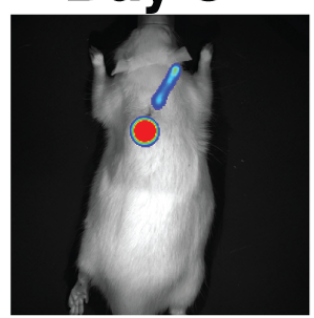

Day 3

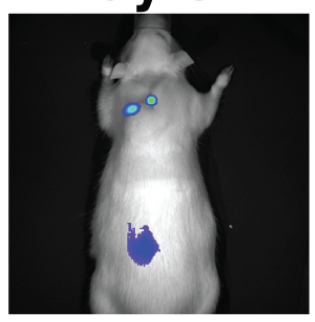

Day 4

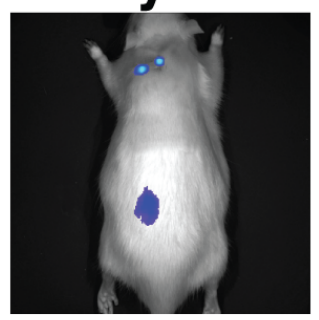

Day 4

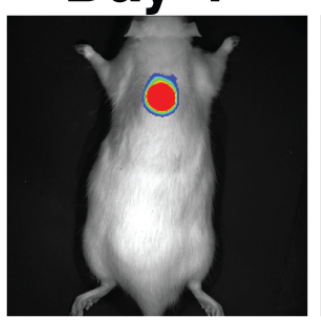

Day 11

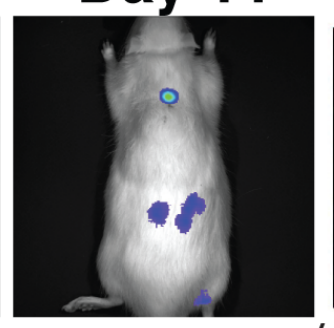

2.5

2. 1.5 1.0

$\mathrm{p} / \mathrm{s} / \mathrm{cm}^{2} / \mathrm{sr}$

$\mathbf{E}$
$\mathbf{G}$

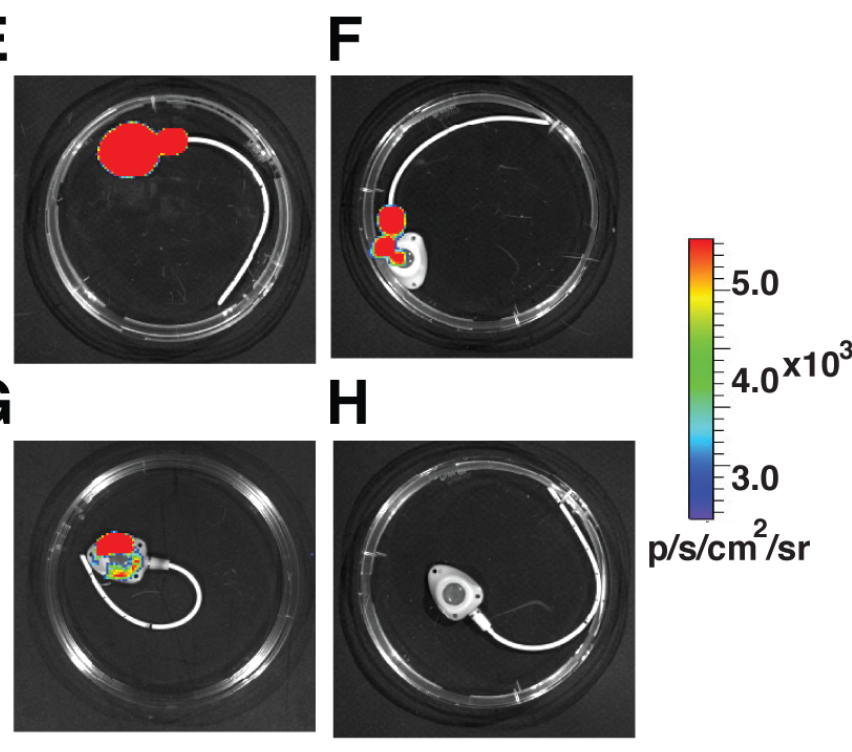

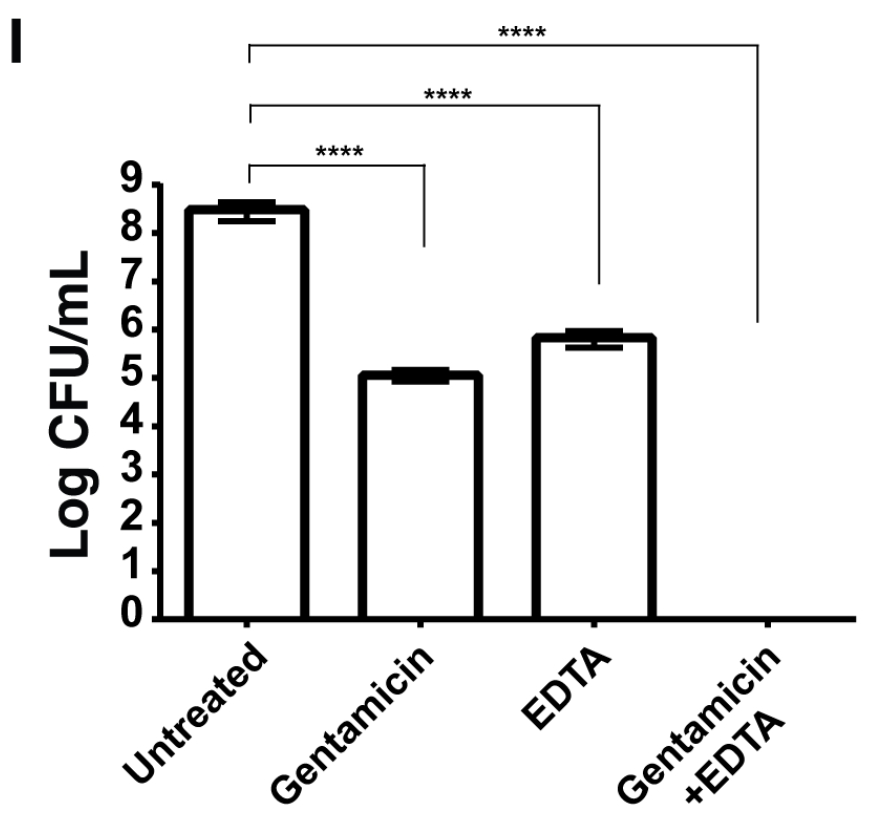

Day 11

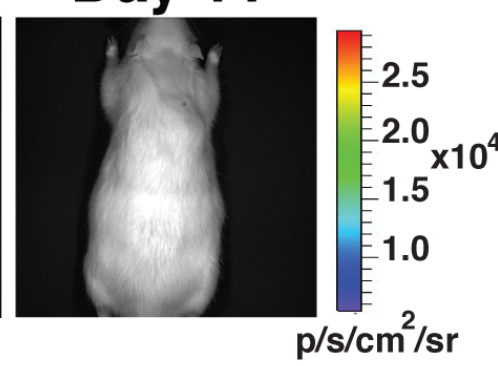

Figure 7 

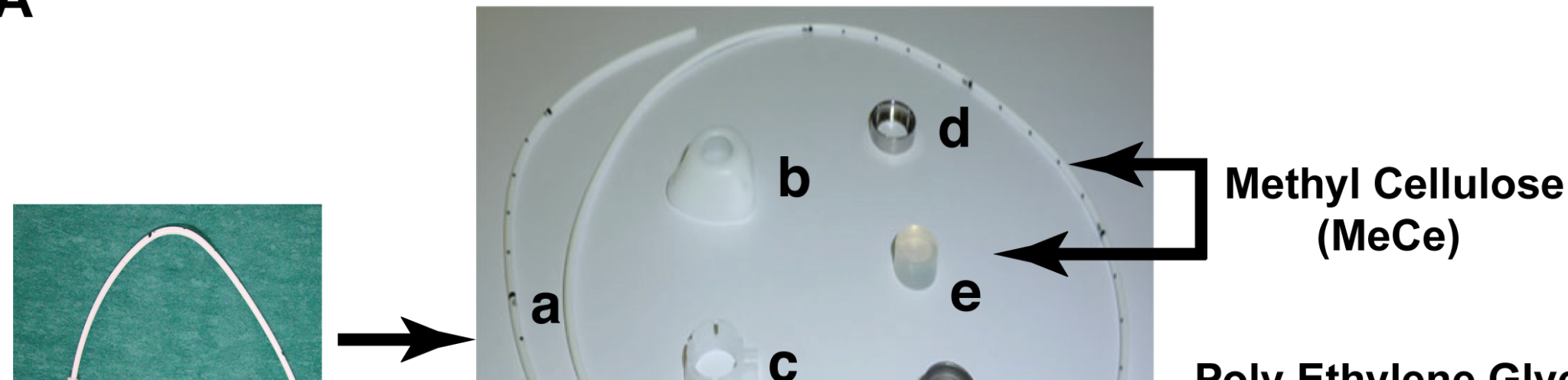

a

C

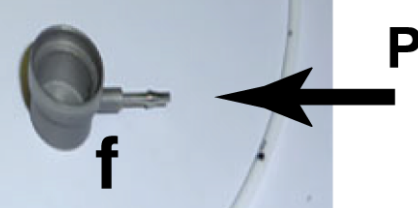

Poly Ethylene Glycol (PEG)

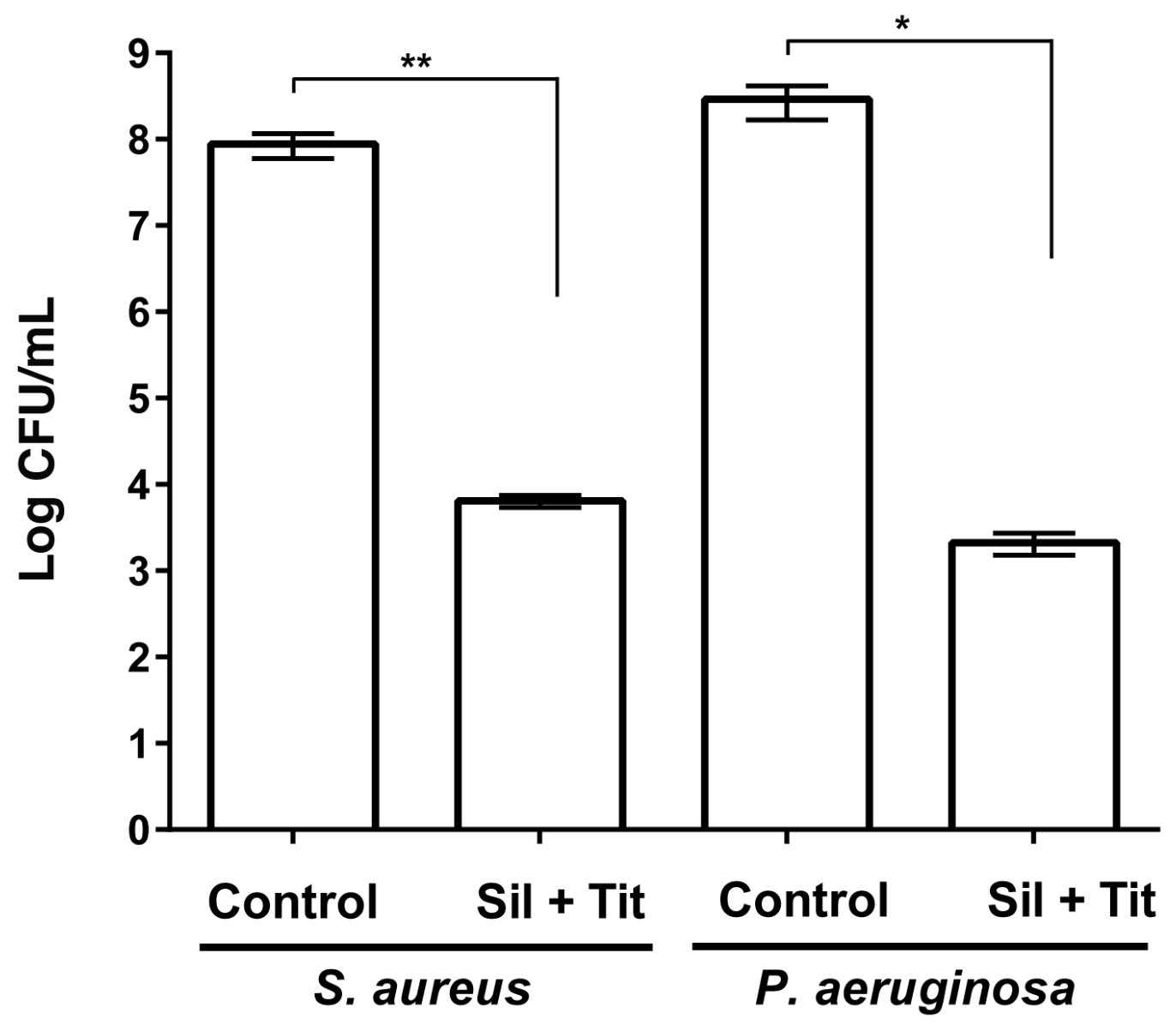

Figure 8 